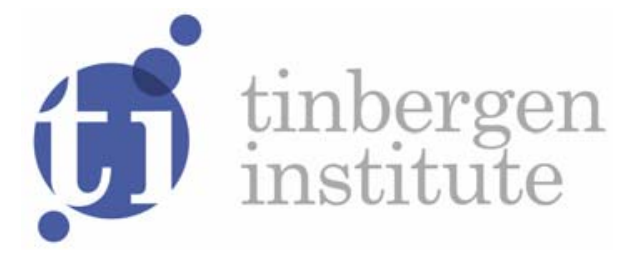

\title{
Measuring the Effectiveness of Anti-Cartel Interventions: \\ A Conceptual Framework
}

Yannis Katsoulacos'

Evgenia Motchenkova ${ }^{2}$

David UIph ${ }^{3}$

1 Athens University of Economics and Business, Athens, Greece;

2 Faculty of Economics and Business Administration, VU University Amsterdam, and Tinbergen Institute, the Netherlands;

3 University of St Andrews, St Andrews, Fife, Great Britain. 
Tinbergen Institute is the graduate school and research institute in economics of Erasmus University Rotterdam, the University of Amsterdam and VU University Amsterdam.

More TI discussion papers can be downloaded at http://www.tinbergen.nl

Tinbergen Institute has two locations:

Tinbergen Institute Amsterdam

Gustav Mahlerplein 117

1082 MS Amsterdam

The Netherlands

Tel.: +31(0)20525 1600

Tinbergen Institute Rotterdam

Burg. Oudlaan 50

3062 PA Rotterdam

The Netherlands

Tel.: +31(0)10 4088900

Fax: +31(0)10 4089031 


\title{
Measuring the Effectiveness of Anti-Cartel Interventions: A Conceptual Framework
}

\author{
Yannis Katsoulacos ${ }^{1}$ \\ Evgenia Motchenkova ${ }^{2}$ \\ David Ulph ${ }^{3}$
}

\begin{abstract}
This paper develops a model of the birth and death of cartels in the presence of enforcement activities by a Competition Authority (CA). We distinguish three sets of interventions: (a) detecting, prosecuting and penalising cartels; (b) actions that aim to stop cartel activity in the short-term, immediately following successful prosecution; (c) actions that aim to prevent the re-emergence of prosecuted cartels in the longer term. The last two intervention activities have not been analysed in the existing literature. In addition we take account of the structure and toughness of penalties. In this framework the enforcement activity of a CA causes industries in which cartels form to oscillate between periods of competitive pricing and periods of cartel pricing. We determine the impact of CA activity on deterred, impeded, and suffered harm. We derive measures of both the total and the marginal effects on welfare resulting from competition authority interventions and show how these break down into measures of the Direct Effect of interventions (i.e. the effect due to cartel activity being impeded) and two Indirect/Behavioural Effects - on Deterrence and Pricing. Finally, we calibrate the model and estimate the fraction of the harm that CAs remove as well as the magnitude of total and marginal welfare effects of anti-cartel interventions.
\end{abstract}

JEL Classification: L4 Antitrust Policy, K21 Antitrust Law, D43 Oligopoly and Other Forms of Market Imperfection, C73 Stochastic and Dynamic Games; Repeated Games

Keywords: Antitrust Enforcement, Antitrust Law, Cartel, Oligopoly, Repeated Games.

\footnotetext{
${ }^{1}$ Department of Economic Science, Athens University of Economics and Business, Patission 76, Athens 104 34, Greece, Email: katsoul@aueb.gr or ysk@hol.gr

2 Department of Economics, VU University Amsterdam, TILEC and Tinbergen Institute, De Boelelaan 1105, 1081 HV Amsterdam, The Netherlands, Email: emotchenkova@,feweb.vu.nl

${ }^{3}$ University of St Andrews, School of Economics and Finance, St Andrews, Fife, KY16 9AR, Scotland, UK;

Director Scottish Institute for Research in Economics (SIRE), Email: du1@st-andrews.ac.uk
} 


\section{Introduction}

In a recent briefing note for a conference that they were organizing ${ }^{4}$, high level representatives of the Dutch, European and UK Competition Authorities stated: "Many Competition Authorities use imperfect but accepted methodologies for calculating the direct impact of competition policy interventions on consumers. In contrast, we are not aware of any methodologies used by Competition Authorities to assess, let alone estimate, the deterrence effects of their work and to assess its macroeconomic impact. Such a methodology would be highly relevant for Competition Authorities as it would allow them to assess the total effect of their interventions and give a clearer picture of the impact of their work on the economy as a whole. In addition, taking deterrence effects into account could be informative for the prioritisation of resources across tools: if the relative size of the deterrence effects varies across tools, then using only the direct effects for resource allocation and prioritisation would be a mistake. It would also be interesting to understand better how deterrent mechanisms and effects have varied in the past depending on differences in competition policy enforcement."

The aim of this paper is to provide a conceptual framework that precisely addresses all these issues, albeit in the specific context of anti-cartel interventions. Our approach is microeconomic rather than macroeconomic, but the aim is still to examine the total impact on aggregate welfare of interventions by a competition authorities.

A comprehensive survey of the methodologies currently used for assessing the effectiveness of a Competition Authority (hereafter CA) in enforcing competition policy, including policy towards cartels, is contained in Davies and Ormosi (2010 and 2012). ${ }^{5}$

As we explain more fully below, our framework involves modelling the birth and death of cartels. In that regard it is very similar to work by Harrington and Chang $(2009,2015){ }^{6}$ Harrington and Chang (2009) in particular is a major contribution since it is the first paper to establish conditions under which observable changes in the number of discovered cartels and the duration of cartels can be effective proxies for the change in the unobservable total number of cartels in existence and so can help us understand how this is affected by specific antitrust policies. ${ }^{7}$ Our work differs from theirs since our objective is to provide a general framework for evaluating the effects on welfare of a wider range of policy instruments than

\footnotetext{
4 “ Looking Beyond the Direct Effects of the Work of Competition Authorities: Deterrence and Macroeconomic Impact", 17-18 September 2015, Brussels.

${ }^{5}$ Evaluations of Competition Policy in general are contained in Baker (2003) and Werden (2008). Davies and Ormosi (2010), review a range of methodological approaches to evaluating competition policy. Studies using particular approaches to evaluate specific aspects of competition policy are set out in Chang and Harrington (2010), Miller (2009) and Ormosi (2014) - the first two of which are concerned with the effects of leniency programs on deterrence and the last one offering an alternative methodology to identifying the fraction of detected cartels. For experimental work trying to obtain a direct measurement of deterrence in a controlled laboratory environment see Bigoni et.al. (2012). Finally, there is work using survey methodologies such as that of Deloitte (2007) and London Economics (2011) commissioned by OFT showing, respectively, that for each cartel detected by a CA at least another 5 (28) are deterred.

${ }^{6}$ There is a series of closely related papers by Harrington $(2004,2005,2011,2014)$

${ }^{7}$ Harrington and Chang (2015) extend this approach to analysis of the effects of leniency programs.
} 
they consider, ${ }^{8}$ and since it captures a more comprehensive set of effects, encompassing: the direct effect of detecting and stopping cartels; the indirect-deterrence effect ${ }^{9}$; an indirectprice effect which captures the effect of policies on the price set by those cartels that do form. Moreover we consider both the total and marginal effects of a CA's interventions and show how these can be decomposed into these three effects.

Recent work by Davies and Ormosi (2014) has similar objectives to ours in that they want to measure the welfare effects of a general range of interventions and show how these can be broken down into direct and indirect effects. The question they address is: "how much harm can cartels cause to an economy and how successful are CAs in rectifying that harm?"10 While we also address this question, their conceptual framework and modeling approach is purely statistical and so is very different to ours. They start from the amount of harm that a CA removes as a result of investigating and prosecuting cartels - essentially the Direct Effect that CAs think they can measure that was referred to in our opening quotation. Davies and Ormosi call this Detected Harm. They take as exogenous both the proportion of cartels that are deterred as a result of CA interventions and the proportion of undeterred cartels that are detected, and, assuming certain distributions of these two parameters, work backwards to obtain the distributions of potential harm; of undetected harm and of deterred harm and so various measures of the effectiveness of the CA. Their approach differs fundamentally from ours since they have no model of cartel behaviour and so are unable to examine: (i) the effect of CA interventions on cartel pricing ${ }^{11}$; (ii) marginal effects of CA interventions; (iii) the effect of other enforcement parameters such as the penalty rate on the effectiveness of CA interventions ${ }^{12}$.

Now, as indicated above, Davies and Ormosi (2014) treat detection of harm by a CA as equivalent to the removal of harm by a CA. Indeed on p.8 of their paper they talk about the harm a CA "removes in the case it detects and intervenes". Other papers in the literature e.g. Harrington $(2004,2005)$ - also assume that the detection and successful prosecution of a cartel (leading to the imposition of a penalty) brings it to an end.

\footnotetext{
${ }^{8}$ The policy instruments they examine is a tougher penalty regime and an increase in the detection rate. As we will see below we consider these instruments and an additional two instruments that affect the re-birth of cartels. Essentially Harrington and Chang (2009) do not examine policy instruments that affect their parameter $\kappa$, the cartel rebirth rate.

${ }^{9} \mathrm{We}$ measure this by considering the fraction of those cartels that would have existed in the absence of a Competition Authority that continue to exist in the presence of a CA and its enforcement activities

${ }^{10}$ Davies and Ormosi (2014), page 3.

11 Bos, Davies and Ormosi (2015) contains some analysis of the effects of a CA's penalty regime on cartel pricing. The results largely replicate those in the literature - e.g. Katsoulacos \& Ulph (2013) or Houba, Motchenkova and Wen (2010) - in showing that, when the penalty is imposed on profits then, if the probability of detection increases with the price set by the cartel, the cartel price will be below the monopoly price.

${ }^{12}$ It is interesting to note however that when we set the values of our key intervention parameters to those implicitly assumed by Davies and Ormosi (2014), our calculations of the fraction of potential harm removed by a competition authority are consistent with theirs, showing that a CA can remove between 55 and $85 \%$ of all potential harm depending on the effort devoted to detection and prosecution. However, we also show that this conclusion is at the top end of the range and is very sensitive to Davies and Ormosi's implicit assumptions about the key intervention parameters. Moreover our calculations of other measures of the effectiveness of CA interventions such as the ratio of the Total Effect to the Direct Effect also differ from theirs, showing that the difference in methodologies really matters.
} 
However, Davies and Ormosi (2010) cite evidence that cartels re-emerge in industries in which a cartel had previously been prosecuted by a CA. Connor (2015) also argues that "recidivism is rampant" 13 , and that, in his sample there are: "at least 70 companies with ten or more violations between 1990-2015; scores of same market/same nation cases; many sequential violations, some of which are overlapping and so may not meet the start/stop/start legal definition of recidivism". So the assumption that the detection, prosecution and penalising of a cartel brings cartel activity in an industry to an end, let alone a complete end, seems unrealistic.

The polar opposite assumption - that cartels continue in existence even if they are detected, successfully prosecuted and penalised - is made in other papers in the literature, e.g. Motta and Polo (2003), Rey (2004), Katsoulacos, Motchenkova and Ulph (2015). A justification for this assumption is that, when cartels form they anticipate the possibility of being detected, prosecuted and penalised; consequently, when this actually happens, it is treated as just a realisation of one of many anticipated risks they face, and, if nothing else has changed, if it was profitable to be in a cartel before prosecution it would remain profitable after prosecution. However this too seems implausible, because if, following a successful prosecution, CAs implement certain interventions, some things might change following a successful prosecution: ${ }^{14}$

- depending on the sanctioning regime in force, all the key personnel involved in operating the cartel might be jailed, or even debarred, so the capacity to form a cartel might be removed;

- CAs might intensively monitor prices and other activities in that industry, increasing the risk of detection, and so reducing the incentive to form a cartel.

Moreover, under this assumption (that cartels continue in existence after prosecution) CA interventions would have no Direct Effect, so it is an inappropriate basis for studying the relationship between the Direct Effect and Indirect Effects of CA interventions.

The paper closest to our analysis is that of Harrington and Chan (2009) who assume that successful prosecution of a cartel in an industry will bring cartel activity to a stop immediately after prosecution but allow for the possibility that a cartel may re-emerge in the same industry at a future date. However they do not explain why prosecution in itself brings a cartel to an end (albeit temporarily), and the assumption seems inconsistent with Connor's evidence of sequential cartel activity.

What none of the existing literature allows for is the possibility that, following a successful prosecution, a cartel might come to an immediate end (but also might not), and that, if it does,

${ }^{13}$ Connor (2015) slide 44. One does however have to treat these results with some caution, since Connor classifies recidivism as being present if a single firm is in two (potentially quite different) cartels at different points of time, rather than if the same, or equivalent, cartel emerges in a given industry/market at two different points of time.

${ }^{14}$ Houba, Motchenkova and Wen (2012) make an intermediate assumption that, following a successful prosecution, cartels either stop or continue in existence with some probability. But, as pointed out above, neither of these two alternatives is attractive. 
cartel activity might subsequently re-emerge in the same industry at a later date. This is precisely the possibility that underpins the framework developed in this paper. To capture this set-up we introduce three intervention parameters:

- the probability that in any given period a cartel will be successfully prosecuted and penalised. $^{15}$

- the probability that, in the period immediately following a successful prosecution the industry reverts to competitive behaviour;

- the probability that, if an industry in which a cartel was previously prosecuted is acting competitively at the start of any period, it continues to act competitively at the start of the next period.

The first parameter reflects resources that a CA puts into detection, investigation and prosecution - activities on which much of the literature has focussed. We assume that this is strictly less than 1 to capture the fact that CAs don't have the resources to investigate every industry all the time.

The second and third parameters reflect resources that CAs puts into preventing recidivism following successful prosecutions. To justify having two parameters, it is essential to distinguish between:

- short-term interventions which are implemented for a limited period of time immediately following the successful prosecution of a cartel and which aim to prevent the continuation of price-fixing behaviour by the prosecuted cartel, and

- longer-term interventions potentially involving sustained monitoring of activities in industries in which a cartel has previously been prosecuted.

The reason for making the distinction is as follows. For the relatively small number of industries in which cartels have recently been prosecuted, it is plausible to assume that, for a limited period of time, CAs can monitor activities in these industries with an intensity ${ }^{16}$ that ensures that with a very high probability the price-fixing activity of the prosecuted cartel is brought to an end in the short-run. Indeed this probability could even be unity - the assumption of Davies and Ormosi (2014) and Harrington and Chang (2009). Treating this probability parametrically allows us to test the sensitivity of conclusions to this assumption and is also consistent with Connor's evidence of serial violations, and so the possibility that successful prosecution of a cartel by a CA does not always bring cartel activity to an end, even in the short-run.

However it is implausible that CAs could indefinitely sustain this intense level of monitoring in every industry in which they have ever prosecuted a cartel. Consequently, in the long term

\footnotetext{
${ }^{15}$ Obviously in order to be prosecuted and penalised the cartel will have to have been detected and investigated, so, as in Harrington (2011) one could think of the probability of being successfully prosecuted as being the product of three probabilities: probability of detection , probability of investigation if detected; probability of successful prosecution if investigated.

${ }^{16}$ And, in some jurisdictions, jail or debar officials that were responsible for price-fixing.
} 
there is likely the probability of cartel activity re-emerging ${ }^{17}$ is likely to be higher than in the short-term. We capture this through the third intervention parameter above, for which the only restriction we impose is that the probability is less than unity. It should be noted that these interventions relating to resources that the CA puts into preventing recidivism have not received much if any attention in the literature.

These three intervention parameters give us a very rich framework within which to conceptualise the intervention activities of a $\mathrm{CA}$, and one that encompasses the existing literature as special cases. But, taken together they imply that CAs can at best only disrupt cartel activity, they cannot stop it for ever and prevent it from recurring at some point in the future. Put differently, industries in which cartels are not deterred from forming will oscillate between periods when the industry is competitive and periods when it is cartelised. The lengths of these periods are random variables determined by the magnitudes of the various intervention parameters.

A final feature of the framework is that we explicitly model another enforcement parameter $^{18}$ - the penalty rate. This enables us to address the final issue of concern to CAs as captured in our opening quotation - how the effectiveness of interventions depends on differences in policy enforcement. It will also enable us to examine the effectiveness of intervention activities relative to that of raising the penalty rate.

The key insights and conclusions of this framework are:

- The Direct Effect that CAs measure - what Davies and Ormosi (2014) call Detected Harm - is an imperfect measure of the true Direct Effect, essentially because it fails to reflect the dynamic nature of the environment within which CAs operate where cartel activity is only being disrupted by CA interventions not brought to a complete halt. While the true Direct Effect can sometimes be a little lower than which CAs measure - up to $10 \%$ - it can also be substantially higher - up to 3 times higher.

- Nevertheless, for our central parameter estimates, the Total Effect of CA interventions is between $7.5-8.5$ times as large as the Direct Effect that CAs measure.

- There are strong complementarities between the various intervention parameters and between the Direct Effect of CA interventions and the Indirect Deterrence Effectactions that improve the Direct Effect also increase deterrence.

- If penalties are based on revenue then both the total and marginal Indirect Price Effects of interventions can be negative, though, for most parameter values that we have used, the absolute size is small.

- The marginal effect of an increase in the penalty rate is around ten times smaller than

\footnotetext{
${ }^{17}$ For the purposes of our model it does not matter whether it is the previously prosecuted cartel or some different, but equivalent, cartel that is responsible for this re-emergence of cartel activity.

${ }^{18} \mathrm{We}$ refer to this as an enforcement parameter rather than an intervention parameter because the level of the penalty rate does not depend on the ongoing deployment of resources by the CA.
} 
the marginal effect of an increase in the probability of successful prosecution. ${ }^{19}$

- Potentially the most powerful marginal effect is that of longer-term interventions aiming at preventing recidivism - but this is very sensitive to the existing level of recidivism.

The next section sets out a formal model that captures this framework. Then in section 3 we present the effects of cartels on welfare and in section 4 we decompose these effects in direct and indirect effects and we establish a number of comparative static properties. In section 5 we provide an extensive range of illustrative numerical calculations of the direct and indirect effects, taking into account all available empirical knowledge about various parameters of the model. Section 6 offers concluding remarks.

\section{The Model}

\subsection{Assumptions}

There is a continuum of industries, each producing a homogeneous product with identical constant marginal cost $c$ and demand function $Q(p)$. Industries differ in the exogenous number of firms, $n$, that operate in each industry, as well as in some other parameters as specified below. Within each industry symmetric firms compete in prices. ${ }^{20}$ We let $\pi(p)=(p-c) Q(p), \quad p \geq c$ denote industry profits when the price is $p$. It will also be useful to let $p^{M}(c) \quad\left(\operatorname{resp} . \pi^{M}(c) \equiv \pi\left(p^{M}(c)\right)\right)$ denote the monopoly price (resp. profits) which would prevail if the market were served by a monopolist with constant unit $\operatorname{costs} c$. This price (resp. profit) is taken to be a strictly increasing (resp. decreasing) function of $c$.

We let $p^{C}>c$ denote the price that will prevail if the industry is cartelised. This will be determined below. If a cartel is successfully prosecuted it pays a penalty $\rho B\left(p^{C}\right)$ where $\rho>0$ is the penalty rate and $B\left(p^{C}\right)$ is some base - e.g. revenue, profits, overcharge - which depends in general on the price set by the cartel.

If an industry is such that cartels have been deterred from forming then it remains perfectly competitive with price equal to cost and zero profits. So consider an industry in which cartels have not been deterred. As explained in the introduction, at the start of any period it can be in one of two possible states - cartelised or competitive. Let $V^{C A R T}\left(\right.$ resp. $\left.V^{\text {COMP }}\right)$ denote the expected present value of industry profits if the industry is cartelised (resp. competitive) at the start of any period. What happens in each of these states and the dynamics of how industries move between them is as follows.

(a) Cartelised State

\footnotetext{
${ }^{19}$ It is important to be clear that this statement refers solely to the percentage impact on harm of increasing certain enforcement parameters by a given percentage. It takes no account of the resource costs of bringing about this percentage change.

${ }^{20}$ There is Bertrand competition, so when an industry acts competitively price is driven down to costs and profits are zero. Also if a cartel is to be able to raise price above costs all $n$ firms have to be in it.
} 
If a cartel is in existence there is a probability $\beta, 0<\beta<1$ that it will successfully prosecuted and penalised by the CA. ${ }^{21}$ If undetected the cartel makes profits $\pi\left(p^{C}\right)$ and the industry continues for sure to be in the cartelised state at the start of the next period. If detected and prosecuted the cartel again makes profits $\pi\left(p^{C}\right)$ but has to pay a penalty $\rho B\left(p^{C}\right)$. In addition there is a probability $\gamma, 0 \leq \gamma \leq 1$ that the cartel will be shut down by the CA and so the industry will move to the competitive state at the start of the next period. Parameter $\gamma$ captures the interventions of the authority for preventing short-run recidivism.

So we have the following equation:

$$
\begin{aligned}
V^{C A R T}= & (1-\beta)\left[\pi\left(p^{C}\right)+\delta V^{C A R T}\right]+ \\
& \beta\left\{\left[\pi\left(p^{C}\right)-\rho B\left(p^{C}\right)\right]+\delta\left[\gamma V^{C O M P}+(1-\gamma) V^{C A R T}\right]\right\}
\end{aligned}
$$

where $\delta, \quad 0<\delta<1$ is a common discount factor that is assumed to be used by all industries and by the $\mathrm{CA} .^{22}$

\section{(b) Competitive State}

Here, in the current period, the industry makes zero profits but also faces no risk of being penalised. Because of the efforts the CA puts into preventing recidivism in the long-term there is a probability $\chi, 0<\chi<1$ that the industry remains competitive, and so a probability $1-\chi$ that a cartel re-emerges. So we have

$$
V^{\text {COMP }}=\delta\left[\chi V^{\text {COMP }}+(1-\chi) V^{C A R T}\right]
$$

\subsection{Cartel Profits and the Direct Effect of Interventions}

We can rewrite (1) and (2) as:

$$
V^{C A R T}=\left[\pi\left(p^{C}\right)-\beta \rho B\left(p^{C}\right)\right]+\delta(1-\beta \gamma) V^{C A R T}+\delta \beta \gamma V^{C O M P}
$$

and

$$
V^{C O M P}=\frac{\delta(1-\chi)}{(1-\delta \chi)} V^{C A R T}
$$

Substitute (4) into (3) and, after a bit of re-arranging, we get:

\footnotetext{
${ }^{21}$ In this paper $\beta$ is treated as constant across all industries. In future research we plan to investigate the implications of having it - and other industry characteristics - vary across industries. This would generate distributions of harm etc and so bring our framework closer to the statistical approach of Davies and Ormosi (2014).

${ }^{22} \mathrm{We}$ recognise that $\delta$ is going to vary across industries because of differences in growth rates, non-diversifiable risks etc. As discussed later, this can be allowed for to some extent when dealing with deterrence.
} 


$$
V^{C A R T}=\sigma \cdot \frac{\left[\pi\left(p^{C}\right)-\beta \rho B\left(p^{C}\right)\right]}{1-\delta}
$$

where

$$
\sigma=\frac{1}{1+\frac{\delta \beta \gamma}{(1-\delta \chi)}} \Rightarrow 0 \leq \sigma \leq 1
$$

As mentioned in the introduction Katsoulacos, Motchenkova and Ulph (2015) assume that cartels always continue in existence following successful prosecution - so $\gamma=0 \Rightarrow \sigma=1$ in their model. So, in their model, once formed, a stable cartel stays in existence for ever. They show that, in these circumstances, the expected present value of cartel profits are:

$$
\frac{\left[\pi\left(p^{C}\right)-\beta \rho B\left(p^{C}\right)\right]}{1-\delta}
$$

Consequently the variable $\sigma$ is the fraction of the value that a cartel would make if it stayed in existence for ever that it actually makes given interventions by a competition authority that disrupt/impede cartel activity and cause the industry to act competitively for certain periods of time. Effectively $\sigma$ measures the fraction of time that an industry is in a cartelised state, ${ }^{23}$ while $(1-\sigma)$ measures the fraction of time in which cartel behaviour is impeded ${ }^{24}$ by a CA's disruptive interventions. We will see below that the Direct Effect of a CA's interventions will be related to the variable $(1-\sigma)$, and that $\sigma$ also affects the level of deterrence that CA interventions achieve. Our framework allows us to disentangle these different effects.

We have the following comparative-static results:

\section{Proposition 1}

(i) $\gamma=0$ implies $\sigma \equiv 1$;

(ii) Given the assumption that $0<\beta<1$, then $\gamma>0$ implies $\sigma<1$ and $\sigma$ is strictly decreasing in $\beta, \gamma$ and $\chi$, taking a minimum value $\underline{\sigma}=1-\delta>0$ when $\beta=\gamma=\chi=1$. $^{25}$

(iii) the penalty rate, $\rho$, has no effect on $\sigma-$ i.e. this enforcement parameter has no Direct Effect.

\footnotetext{
${ }^{23}$ Alternative equivalent interpretations are that it is the fraction of all industries in which cartels exist that exhibit cartel behaviour in any given period, or the probability that a given industry in which a cartel exists behaves in a cartelised fashion in any given period.

${ }^{24}$ We prefer the term "impeded" to the term "detected" that is used by Davies \& Ormosi and others, because, to have any direct effect CAs must do more than just detect and successfully prosecute cartels - they must take actions that bring cartel behaviour to an end and prevent it recurring.

${ }^{25}$ Notice that it then follows from (5) that $V^{C A R T}=\pi\left(p^{C}\right)-\rho B\left(p^{C}\right)$ since, under these conditions, a cartel will only last for a single period, during which it will definitely be penalised.
} 
Proof: These all follow immediately from (6).

The minimum value, $\underline{\sigma}$ provides a measure of the maximal direct effectiveness of $\mathrm{CA}$ interventions.

A final important implication of the formula for $\sigma$ given in (6) is that there are strong complementarities between the intervention parameters in terms of their impact on reducing $\sigma$. So the greater the value of any two parameters the larger will be the percentage reduction in $\sigma$ brought about by an increase in the third intervention parameter.

Formally we have:

\section{Proposition 2}

$$
\begin{aligned}
& -\frac{\partial \sigma}{\partial i} \cdot \frac{i}{\sigma}=(1-\sigma), i=\beta, \gamma ; \quad-\frac{\partial \sigma}{\partial \chi} \cdot \frac{\chi}{\sigma}=(1-\sigma) \frac{\delta \chi}{1-\delta \chi} \\
& \left(-\frac{\partial \sigma}{\partial \chi} \cdot \frac{\chi}{\sigma}\right) \geq\left(-\frac{\partial \sigma}{\partial i} \cdot \frac{i}{\sigma}\right), i=\beta, \gamma \text { as } \delta \chi \frac{1}{<2}
\end{aligned}
$$

Proof: Part (i) follows immediately from differentiation of (6), while part (ii) follows immediately from (i)

\subsection{Cartel Behaviour: Pricing}

If a cartel exists it will choose the price to maximise the expected present value of its profits subject to the ICC (12). As shown in Katsoulacos, Motchenkova and Ulph (2015) in a wide range of cases of interest - e.g. fixed penalties, penalties that are based on revenue or profits - the optimum price is just that which maximises the expected value of profits without any constraint, so, drawing on that analysis we will take it that the cartel price is the unconstrained profit-maximising collusive price:

$$
p^{C}=\underset{p \geq c}{\arg \max }[\pi(p)-\beta \rho B(p)]
$$

which means that the cartel price is a function purely of the toughness of the penalty regime $\tau=\beta \rho$.

We have the following results regarding the cartel price as defined above:

\section{Proposition 3}

(i) The cartel price is independent of the intervention parameters $\gamma$ and $\chi$

(ii) If there were no CA - and so $\beta=0 \Rightarrow \tau=0$ - then the cartel price is the monopoly price, i.e. $p^{C}=p^{M}(c)$.

(iii) If there is a $\mathrm{CA}$ that conducts investigations - and so $\beta>0 \Rightarrow \tau>0$ - then, depending on what penalty base is used, the cartel price can be above or below the monopoly price; 
(iv) The cartel price is a strictly increasing (resp. decreasing) function of $\tau$ depending on whether the cartel price is above (resp. below) the monopoly price. Formally, $\frac{d p^{C}}{d \tau} \geq 0$ as $p^{C} \geq p^{M}$

Proof: (i) Obvious from (8) in which $\gamma$ and $\chi$ do not appear. (ii) again obvious from (8); (iii) follows from Katsoulacos, Motchenkova and Ulph (2015) where it is shown that if the penalty is on revenue and if both the penalty rate and the probability of successful prosecution are independent of the cartel price then the cartel price is unambiguously higher than the monopoly price, ${ }^{26}$ while if the penalty is based on profits the cartel price equals then monopoly price and, if the penalty is based on the overcharge the cartel price is unambiguously lower than the monopoly price; (iv) since, from (8), $p^{C}$ satisfies the f.o.c. $\pi^{\prime}\left(p^{C}\right)-\tau B^{\prime}\left(p^{C}\right)=0$, then, assuming the second-order conditions for a maximum are satisfied, it follows from standard comparative static analysis that $\operatorname{sign}\left(\frac{d p^{C}}{d \tau}\right)=\operatorname{sign}\left[-B^{\prime}\left(p^{C}\right)\right]=\operatorname{sign}\left[-\pi^{\prime}\left(p^{C}\right)\right]$. The result then follows from the fact that $p^{M}=\arg \max \pi(p)$ and consequently $\pi^{\prime}\left(p^{C}\right) \underset{<}{\geq} 0$ as $p^{C} \leq p^{M}$

\subsection{Cartel Behaviour: Deterrence}

\subsubsection{Defection and Incentive Compatibility Constraint}

Given (5) the expected profits per firm from being in a cartel are $\frac{V^{C A R T}}{n}$.

We assume that if a firm defects from the cartel then it undercuts the cartel price, and enjoys the profits from doing so for a single period before the other cartel members react by punishing the defector.

Since we allow for the possibility that the cartel price is above the monopoly price, it follows that, if this is the case, the best price for the defector to set is the monopoly price, while in all other cases the defector will set a price just below the cartel price and so take the entire cartel profits. Consequently the one-period defection profits are: ${ }^{27}$

$$
\pi^{D}\left(p^{C}\right)=\left\{\begin{array}{ll}
\pi^{M}(c), & p^{C}>p^{M}(c) \\
\pi\left(p^{C}\right), & c \leq p^{C} \leq p^{M}(c)
\end{array} .\right.
$$

\footnotetext{
${ }^{26}$ Katsoulacos and Ulph (2013) show that if the penalty is based on revenue but either the probability of investigation or the penalty rate are perceived to be positively related to the cartel price then the cartel will set a lower price than predicted by Katsoulacos, Motchenkova and Ulph (2015) - but it may still be higher than the monopoly price.

${ }^{27}$ This formula for defection profits was first given in Katsoulacos, Motchenkova and Ulph (2015), who also showed that when penalties are imposed on revenue then the cartel price can be above the monopoly price.
} 
We assume that remaining cartel members punish defection by reverting to competitive behaviour in the period immediately after the defection. We assume that with probability $1-\theta$ the remaining cartel members adopt an infinite grim trigger strategy and continue to act competitively for ever more. However, with probability $\theta$ remaining cartel members do not do so, and, in this case we assume that if the industry is in a competitive state at the start of any period following a defection there is only a probability $\xi, 0 \leq \xi \leq 1^{28}$ that the industry will continue to be competitive at the start of the following period. If the industry does not remain competitive and reverts to a cartel at the start of the next period then its future profits will be given by $V^{C A R T}$ as given by (5) above. If we define $\widetilde{V}^{\text {COMP }}$ as the expected present value of profits of an industry that is in the competitive state at the start of a period following a defection but has not implemented a grim trigger strategy. This will satisfy the recursive equation

$$
\tilde{V}^{\text {COMP }}=\delta\left[\xi \tilde{V}^{\text {COMP }}+(1-\xi) V^{C A R T}\right]
$$

Given this, the Incentive Compatibility Constraint (ICC) - the condition that the expected present value of remaining within the cartel are at least as high as those of defecting - is:

$$
\frac{V^{C A R T}}{n} \geq \pi^{D}\left(p^{C}\right)+\delta \theta \frac{\tilde{V}^{\text {COMP }}}{n}=\pi^{D}\left(p^{C}\right)+\frac{\delta^{2} \theta(1-\xi)}{1-\delta \xi} \frac{V^{C A R T}}{n}
$$

which, on substituting (5), becomes:

$$
\frac{\left[\pi\left(p^{C}\right)-\beta \rho B\left(p^{C}\right)\right]}{n(1-\delta)}\left[1-\frac{\delta^{2} \theta(1-\xi)}{1-\delta \xi}\right] \sigma \geq \pi^{D}\left(p^{C}\right)
$$

So now let

$$
\Delta=\frac{n(1-\delta)}{\left[1-\frac{\delta^{2} \theta(1-\xi)}{1-\delta \xi}\right]}
$$

be what we call the intrinsic difficulty ${ }^{29}$ of holding the cartel together, and the ICC can be written

\footnotetext{
28 Harrington and Chang $(2009,2015)$ assume that the probability of a cartel re-emerging is the same whether the industry is in a competitive state because of an intervention by a CA or because of a defection. Essentially they assume that $\xi=\chi$. However we allow these probabilities to be different because they depend on very different behaviours: $\xi$ depends on the behaviour of cartel members and their willingness to continue to forego cartel profits to punish a past defection; $\chi$ depends on efforts by a CA to prevent recidivism by, say, continuing to intensively monitor industries in which it previously prosecuted a cartel.

${ }^{29}$ This is a generalisation of the formula in Katsoulacos, Motchenkova and Ulph (2015) where it is assumed that firms always implement the standard grim trigger strategy and so in all industries $\theta=0 \Rightarrow \Delta=n(1-\delta)$.
} 


$$
\frac{\left[\pi\left(p^{C}\right)-\beta \rho B\left(p^{C}\right)\right]}{\Delta} \sigma \geq \pi^{D}\left(p^{C}\right) .
$$

Notice that $\Delta$ can vary across industries with $n, \theta$ and $\xi^{30}$. We can also allow for some variation in $\delta$ across industries and that, by assumption, the remaining parameters in (12) are exogenous constants and do no not depend on any enforcement parameters chosen by the CA.

\subsubsection{Deterrence}

Given the cartel price we can now define the critical level of difficulty, $\bar{\Delta}$, for which the ICC just holds. From (13) this is defined by:

$$
\bar{\Delta}=\sigma \frac{\pi\left(p^{C}\right)-\beta \rho B\left(p^{C}\right)}{\pi^{D}\left(p^{C}\right)} .
$$

It then follows from (13) that:

- for those industries for which $\Delta \leq \bar{\Delta}$, the inequality in (13) holds, stable cartels will exist and these industries will oscillate between periods of cartelisation and periods of competitions as the disruptive interventions of the CA force the break up cartels and enforce periods of competition;

- for those industries for which $\Delta>\bar{\Delta}$ the inequality in (13) fails to hold, so no stable cartels exist and these industries remain in a state of permanent competition.

We can re-write (14) as

$$
\bar{\Delta}=\sigma \bar{\Delta}^{0}(\tau) \text { where } \bar{\Delta}^{0}(\tau)=\frac{\pi\left(p^{C}\right)-\tau B\left(p^{C}\right)}{\pi^{D}\left(p^{C}\right)},
$$

where $\bar{\Delta}^{0}(\tau)$ is the critical level of difficulty that would arise if $\gamma=0 \Rightarrow \sigma=1$ and so CA interventions never shut down cartels, even temporarily. It is the expression for the critical level of deterrence that appears in Katsoulacos, Motchenkova and Ulph (2015).

Notice that, since $p^{C}$ is a function solely of the toughness of the penalty regime, $\tau=\beta \rho$, so too is $\bar{\Delta}^{0}(\tau)$. This gives rise to the following important insight:

Proposition 4: For any given degree of toughness of the penalty regime, $\tau=\beta \rho$, actions taken by a CA to increase the direct effect of its interventions (i.e. reduce $\sigma$ ) automatically also increase the indirect deterrence effect of its interventions (i.e. reduce $\bar{\Delta}$ ).

Proof: Follows immediately from (15)

\footnotetext{
${ }^{30}$ We can also allow for the possibility of some variation in $\delta$ away from the "typical" value assumed in the rest of the analysis. Given the analysis of deterrence that we undertake below, this may help explain why some specific industries have stable cartels while in others they fall apart very quickly.
} 
To obtain more detailed comparative static predictions about deterrence, we first provide the following Lemma:

Lemma If $p^{C} \geq p^{M}$ then $\frac{d \bar{\Delta}^{0}(\tau)}{d \tau}<0$.

Proof: From (8) $p^{C} \geq p^{M}$ implies $\bar{\Delta}^{0}(\tau)=\frac{\pi\left(p^{C}\right)-\tau B\left(p^{C}\right)}{\pi\left(p^{M}\right)}$ and so, from (13) and the Envelope Theorem we have $\frac{d \bar{\Delta}^{0}(\tau)}{d \tau}=-\frac{B\left(p^{C}\right)}{\pi\left(p^{M}\right)}<0$

Notice that if $p^{C}<p^{M}$ then, from (8), $\bar{\Delta}^{0}(\tau)=\frac{\pi\left(p^{C}\right)-\tau B\left(p^{C}\right)}{\pi\left(p^{C}\right)}$ and then

$$
\frac{d \bar{\Delta}^{0}(\tau)}{d \tau}=\left(-\frac{B\left(p^{C}\right)}{\pi\left(p^{C}\right)}\right)+\left\{\frac{\left[\pi\left(p^{C}\right)-\tau B\left(p^{C}\right)\right]}{\left[\pi\left(p^{C}\right)\right]^{2}}\right\} \pi^{\prime}\left(p^{C}\right)\left(-\frac{d p^{C}}{d \tau}\right)
$$

where the first term on the RHS of (16) follows once again from the Envelope Theorem and is unambiguously negative. However given Proposition 3(iv) it follows that if $p^{C}<p^{M}$ then every component of the expression in the second term on RHS of (16) is positive, so, at this level of generality, it is impossible to unambiguously determine the sign of $\frac{d \bar{\Delta}^{0}(\tau)}{d \tau}$. However it is clear that in a very wide range of circumstances it will be negative. So in all that follows we assume:

$$
\frac{d \bar{\Delta}^{0}(\tau)}{d \tau} \cdot \frac{\tau}{\bar{\Delta}^{0}(\tau)}<0
$$

We then have the following comparative static results regarding deterrence:

\section{Proposition 5}

(i) If there were no CA - and so $\beta=0$ - then $\sigma=1$ and $\widetilde{\Delta}=1$ and so $\bar{\Delta}=1$

(ii) If a CA undertakes investigations- and so $\beta>0$ - then $\tilde{\Delta}<1 \Rightarrow \bar{\Delta}<1$.

(iii) $\frac{\partial \bar{\Delta}}{\partial \beta} \cdot \frac{\beta}{\bar{\Delta}}=\frac{\partial \sigma}{\partial \beta} \cdot \frac{\beta}{\sigma}+\frac{d \bar{\Delta}^{0}(\tau)}{d \tau} \cdot \frac{\tau}{\bar{\Delta}^{0}(\tau)}<0 ; \quad \frac{\partial \bar{\Delta}}{\partial \gamma} \cdot \frac{\gamma}{\bar{\Delta}}=\frac{\partial \sigma}{\partial \gamma} \cdot \frac{\gamma}{\sigma}<0 ; \quad \frac{\partial \bar{\Delta}}{\partial \chi} \cdot \frac{\chi}{\bar{\Delta}}=\frac{\partial \sigma}{\partial \chi} \cdot \frac{\chi}{\sigma}<0$;

(iv) $\frac{\partial \bar{\Delta}}{\partial \rho} \cdot \frac{\rho}{\bar{\Delta}}=\frac{d \bar{\Delta}^{0}(\tau)}{d \tau} \cdot \frac{\tau}{\bar{\Delta}^{0}(\tau)}<0$.

Proof: (i) Follows from (6) and from Part (ii) of Proposition 3 which implies $\pi^{D}\left(p^{C}\right)=\pi\left(p^{C}\right)$; (ii) follows from the fact that $\pi\left(p^{C}\right)-\beta \rho B\left(p^{C}\right)<\pi\left(p^{C}\right) \leq \pi^{D}\left(p^{C}\right)$; 
(iii) follows from (15), Proposition 2(i) and (17); (iv) follows from (15), Proposition 1 (iii) and (17).

Taken together parts (i) and (ii) imply that $\bar{\Delta}$ defines the fraction of the benchmark industries $^{31}$ that will cartelise (albeit only intermittently) in the presence of an active CA and its anticipated disruptive interventions and penalty regime, while for those benchmark industries for which $\bar{\Delta}<\Delta \leq 1$, cartels will be deterred from forming in the presence of an active CA. So $\bar{\Delta}$ gives us a precise measure of the deterrent effect of a CA's enforcement actions. Parts (iii) and (iv) of the proposition tell us that all four enforcement parameters $\beta, \chi, \gamma$ and $\rho$ - improve deterrence (lower $\bar{\Delta}$ ), but they work through different channels: $\chi$ and $\gamma$ work only through their effect on $\sigma ; \rho$ works only through its effect on $\bar{\Delta}^{0}$; while $\beta$ works through both channels.

\section{Cartels and Welfare}

Having determined how the intervention parameters $\beta, \gamma$ and $\chi$ and the penalty rate $\rho$ affect the three key variables $\sigma, \bar{\Delta}$ and $p^{C}$ that are related, respectively, to the direct effect and the two indirect effects on deterrence and price we can now derive expressions for welfare and how this changes with these enforcement parameters.

We assume that the relevant welfare objective for a $\mathrm{CA}$ is consumer surplus ${ }^{32}$ and let $C S(p)=\int_{p}^{\infty} Q(x) d x$ denote the flow of consumer surplus in a period when the price is $p$.

To begin, consider industries for which $0 \leq \Delta \leq \bar{\Delta}$ and so cartels might exist for certain periods of time. Let $W^{C A R T}$ be the expected present value of consumer surplus when, at the start of a period a cartel is in existence and let $W^{\text {СOMP }}$ denote the expected present value of welfare when, at the start of a period the industry is temporarily competitive. By analogy with (3) and (4) these satisfy the recursive equations

$$
W^{C A R T}=C S\left(p^{C}\right)+\delta(1-\beta \gamma) W^{C A R T}+\delta \beta \gamma W^{C O M P}
$$

and

$$
W^{\text {COMP }}(1-\delta \chi)=C S(c)+\delta(1-\chi) W^{C A R T}
$$

As before we can solve to get

$$
W^{C A R T}=\frac{\sigma C S\left(p^{C}\right)+(1-\sigma) C S(c)}{1-\delta},
$$

\footnotetext{
${ }^{31}$ Those with $\Delta \leq 1$ that would have cartelised had there been no CA.

${ }^{32}$ Everything that follows will go through in a completely analogous fashion if the CA uses a total welfare standard, and just replace the function $C S(p)$ with $T W(p)=C S(p)+\pi(p)$.
} 
where $\sigma$ is once again given by (6).

The expression in (20) is directly analogous to that in (5), the main difference being that, in periods when the industry is temporarily competitive, net private profits are zero whereas consumer surplus is positive - and indeed larger than when the industry is cartelised. Define $C S^{C A R T}=(1-\delta) W^{C A R T}$ as the constant per-period flow of consumer surplus whose present value would by $W^{C A R T}$, and then (20) becomes: .

$$
C S^{C A R T}=\sigma C S\left(p^{C}\right)+(1-\sigma) C S(c) .
$$

Taking account of the fact that stable cartels exist in only a fraction $\bar{\Delta}, \quad 0 \leq \bar{\Delta} \leq 1$ of the industries in which they would have existed had there been no CA, while the remaining fraction of industries are competitive and generate a permanent flow of consumer surplus $C S(c)$, we can define the average consumer surplus that arises in this benchmark set of industries from having an active $\mathrm{CA}$ in place as

$$
\overline{C S}=\bar{\Delta} C S^{C A R T}+(1-\bar{\Delta}) C S(c) .
$$

From (21) this becomes

$$
\overline{C S}=C S(c)-\bar{\Delta} \sigma\left[C S(c)-C S\left(p^{C}\right)\right] .
$$

So average consumer surplus is just the consumer surplus that would arise if all the benchmark industries were competitive minus the loss of surplus that arises from having cartels form in a fraction $\bar{\Delta}$ of these industries, but where, because of the disruptive actions of the CA, this loss amounts to only a fraction $\sigma$ of the loss of consumer surplus $\left[C S(c)-C S\left(p^{C}\right)\right]$ that would arise if these cartels were permanently in existence.

To capture this intuition more formally we can re-write (23) as:

$$
\overline{C S}=C S(c)-H\left(\sigma, \bar{\Delta}, p^{C}\right)
$$

where,

$$
H\left(\sigma, \bar{\Delta}, p^{C}\right)=\bar{\Delta} \sigma\left[C S(c)-C S\left(p^{C}\right)\right]
$$

is the Harm ${ }^{33}$ Actually Suffered by an economy because of cartels. This harm arises only in

(i) those industries where cartels are not deterred;

(ii) for these industries only for the fraction of time when the harm is not impeded by CA interventions.

Associated with these situations where, due to CA interventions, harm is prevented from arising, we define the amount of:

${ }^{33}$ That is loss of consumer surplus 
- Deterred Harm as $(1-\bar{\Delta})\left[C S(c)-C S\left(p^{C}\right)\right]$;

- Impeded Harm as $\bar{\Delta}(1-\sigma)\left[C S(c)-C S\left(p^{C}\right)\right]$.

Notice that both of these depend on the price, $p^{C}$, set by the cartel, since they reflect the amount of harm that would have been suffered had cartels not been deterred/impeded. ${ }^{34}$

Drawing on the discussion of Davies and Ormosi (2014) we can also define the Potential Harm, $H^{0}$, as that which would arise if there were no CA. In such a situation we would have $\beta=0$ which, from the analysis in Section 2, implies $\sigma=1, \quad \tau=0 \Rightarrow p^{C}=p^{M}$ and consequently $\bar{\Delta}=1$ and so from (25),

$$
H^{0}=C S(c)-C S\left(p^{M}\right)
$$

Figures 1 and 2 illustrate both actual harm, $H$ and potential harm $H^{0}$.

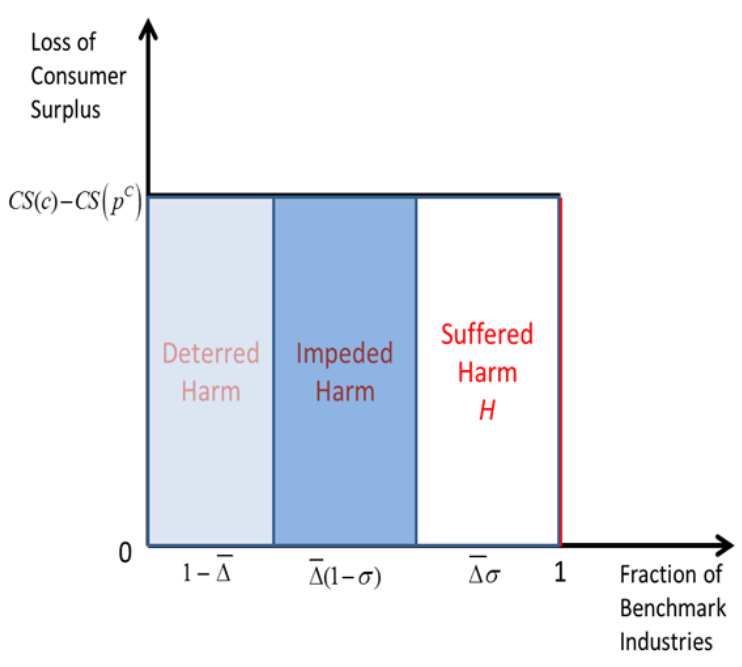

Figure 1: Harm Actually Suffered, $H$

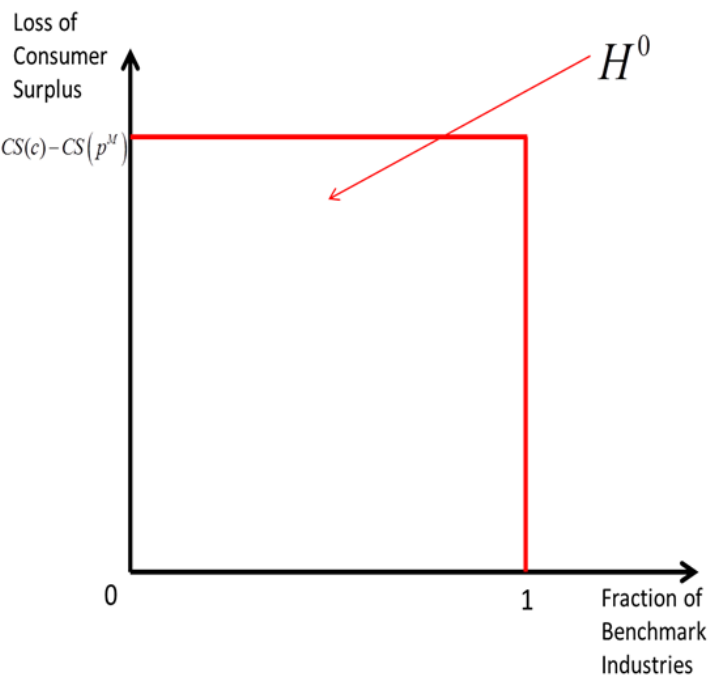

Figure 2: Potential Harm, $H^{0}$

The expressions in (23) - (26) are central to all our analysis of the direct and indirect effects on welfare of CA interventions, to which we now turn.

\section{Direct and Indirect Welfare Effects of Anti-Cartel Policies}

Given the measure of average consumer surplus in (23) there are two issues that we can address.

\footnotetext{
${ }^{34}$ Of course, as in Katsoulacos, Motchenkova and Ulph (2015) the actual amount of harm arising in industries where cartels have been deterred/impeded is zero, whereas Deterred/Impeded Harm measures the harm that would have been suffered had cartels NOT been deterred/impeded.
} 
The first is the calculation of the total welfare benefit that society obtains from having an active competition authority in place. By comparing this to the total value of the resources that have been given to the CA we can determine the benefit-cost ratio it is obtaining from those resources and so whether it is achieving any target ratio that has been set. ${ }^{35}$ Two related sub-issues are:

- how to decompose the total welfare effect into a direct effect plus two indirect effects - on price and deterrence;

- the size of the currently unmeasured indirect effects relative to the direct effect that CAs think they can currently measure - at least to some degree.

Answering this second sub-issue helps a CA understand by how much it can scale up its measure of the direct effect to obtain a measure of the total effect.

The second issue is to calculate the marginal effects of putting more resources into the various kinds of interventions. This is important in helping CAs decide whether they are putting the right amount of resources into the various kinds of interventions in a particular area of anti-trust enforcement - e.g. investigations vs resources used in keeping industries competitive once cartels have been closed down. But it could also be relevant to deciding whether resources should be switched between different areas of antitrust enforcement - e.g. mergers vs cartels vs dominance cases. There are three related sub-issues:

- how to decompose these marginal benefits into a marginal direct effect plus the two marginal indirect effects - on price and deterrence;

- the size of the currently unmeasured marginal indirect effects compared to any of the marginal direct effects that CAs may be able to measure - at least to some degree;

- understanding whether and why the ratio of the sum of the marginal indirect effects to the marginal direct effect might vary systematically across different types of intervention; different areas of anti-trust enforcement; and different industries.

This final issue is important because, if this ratio were constant, then resource deployment could be determined solely on the basis of the marginal direct effects.

We consider the two issues in turn.

\subsection{The Total Welfare Benefit of a Competition Authority}

There are a number of ways that one might think about measuring the total benefit that arises from having a CA in operation. One rather natural way is to compare the value of the average consumer surplus when there is an active competition authority in place - as given by (23) with the average consumer surplus in the counterfactual of having no CA in place. The discussion of Potential Harm above set out the implications of there being no CA. Using this approach, the Total Effect (TE) of having an active competition authority is:

\footnotetext{
${ }^{35} 10: 1$ in the case of the CMA.
} 


$$
T E=\overline{C S}\left(p^{C}\right)-C S\left(p^{M}\right)=C S(c)-\bar{\Delta} \sigma\left[C S(c)-C S\left(p^{C}\right)\right]-C S\left(p^{M}\right)
$$

where the second expression follows by substituting (23).

However, it is easy to check that, from (25) and (26), this is equivalent to defining the Total Effect (TE) of having an active competition authority as being the difference between the Potential Harm and the actual harm. So we have

$$
T E=H^{0}-H\left(\sigma, \bar{\Delta}, p^{C}\right)
$$

Turning to the issue of how to decompose this into a Direct Effect and two Indirect Effects, we can rearrange the expression in (26) to obtain:

$$
\begin{gathered}
T E=\left\{\bar{\Delta}(1-\sigma)\left[C S(c)-C S\left(p^{C}\right)\right]\right\}+ \\
\left\{(1-\bar{\Delta})\left[C S(c)-C S\left(p^{C}\right)\right]\right\}+ \\
\left\{C S\left(p^{C}\right)-C S\left(p^{M}\right)\right\}
\end{gathered}
$$

The first term on the RHS of (29) is the Direct Effect $(D E)$ of having an active CA in place. For those industries in which cartels are not deterred it shows the gain in consumer surplus from blocking cartel activity for a certain fraction of time through disruptive interventions by the CA. This is what we defined above as Impeded Harm. It is a close analogue of what Davies and Ormosi (2014) call Detected Harm $^{36}$ - although, as we will explain below, what they and competition authorities actually measure as the direct effect/detected harm is somewhat different from the Direct Effect as defined above. Notice that the Direct Effect is larger:

- the smaller is $\sigma$ - so the more effective is the CA at blocking harm;

- the larger is $\bar{\Delta}$ - so the less effective is the CA in deterring cartels ${ }^{37}$;

- the higher is $p^{C}$ - so the less effective is the $\mathrm{CA}$ in driving down the price set by cartels.

So, as noted by Davis \& Ormosi (2014), Sorgard (2015) ${ }^{38}$ and others, a large Direct Effect may not always be a source of congratulation for a CA.

\footnotetext{
${ }^{36}$ As explained above in footnote 21 , theirs is a potentially misleading description of what the Direct Effect captures, since, as we stressed above in the introduction and in Proposition 1, in order to have a positive Direct Effect - i.e. in order to have $\sigma<1$ - CAs have to do more than just detect and prosecute cartels - they have to take actions to stop them - even if only temporarily. Davies and Ormosi (2014) recognise this because, on p.8, they talk about the harm a CA "removes in the case it detects and intervenes", so they implicitly assume that detection automatically leads to the removal of harm, and so, at the very least, are effectively assuming that $\gamma=1$. To the extent that the removal of harm is permanent they may also be implicitly assuming that $\chi=1$.

${ }^{37}$ This observation suggests there could be potential incentive problems for a CA trying to pursue a policy of directing resources to maximise the total effect of its actions. For if staff performance is assessed on effectiveness of clearing up cases, then there could be advantages in having a weak deterrent effect since there would be a larger pool of cases to be worked with some "low hanging fruit" to be picked.
} 
The second term on the RHS of (29) is the Indirect Deterrence Effect (IDE) of having a CA. for it measures the gain in consumer surplus that society obtains because the anticipated enforcement activities of the CA deter cartels from forming in a fraction $(1-\bar{\Delta})$ of the benchmark industries. As noted above, following Davies and Ormosi (2014), we can also refer to this as the amount of Deterred Harm. Notice that the expression for Deterred Harm does not contain $\sigma$, for the very good reason that, if a CA deters cartels from forming in certain industries, society obtains all of the benefit from its doing so irrespective of what proportion of harm the CA would have blocked had cartels actually formed. However, as noted above, the better is the CA at blocking harm - i.e. the lower is $\sigma-$ the larger is $(1-\bar{\Delta})$ and so the greater is the magnitude of Deterred Harm. However, as with Impeded Harm, the magnitude of Deterred Harm is greater the higher the price that would have been set by cartels.

The third term on the RHS of (29) is the Indirect Price Effect (IPE). For it measures the impact on consumer surplus that arises because, anticipating the intervention of the CA, cartels now set the price $p^{C}$ rather than the price $p^{M}$ that they would have set had there been no CA. Notice that the expression for this effect contains neither $\bar{\Delta}$ nor $\sigma$ and applies for the entire benchmark. This is because, as discussed above, the effects that a CA's activities have on the price set by cartels affects the magnitudes of Deterred Harm and Impeded Harm as well as the harm actually suffered. Notice also that if $p^{C}>p^{M}$ the Indirect Price Effect will be negative.

So we have the following simple arithmetical decomposition ${ }^{39}$ of the Total Effect:

$$
T E=D E+I D E+I P E
$$

Figure 3 below illustrates Potential Harm, $H^{0}$, harm actually suffered, $H$ and the decomposition of the Total Effect $\left(T E=H^{0}-H\right)$ into these three effects. It is drawn for the case where $p^{C}<p^{M}$.

\footnotetext{
${ }^{38}$ However neither Davies and Ormosi (2014) nor Sorgard (2015) take any account of the indirect price effect, so their comments are based purely on the observation that a large direct effect could be consistent with a weak deterrent effect.

${ }^{39}$ Once again this is rather different from Davies and Ormosi (2014) who assume a multiplicative decomposition.
} 


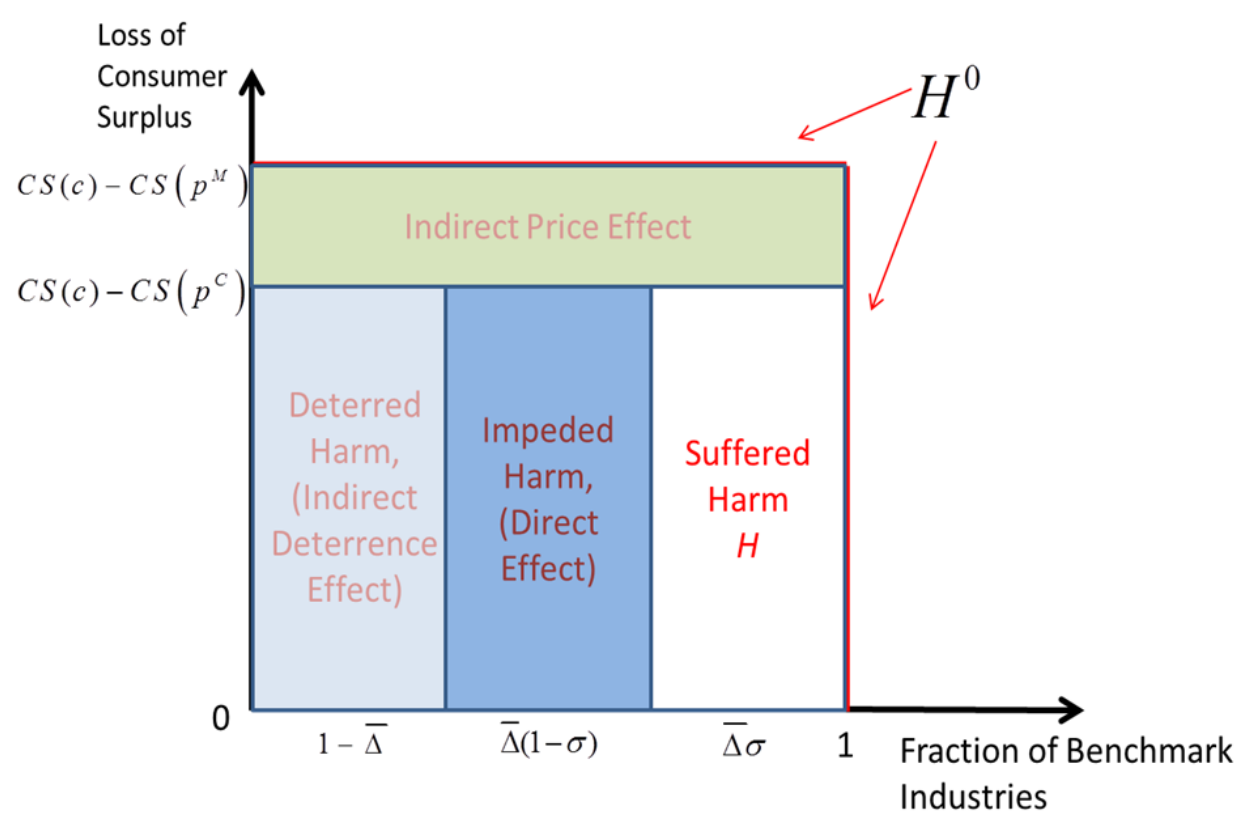

Figure 3: Total Effect, $T E=H^{0}-H$

Notice that, even though there are complex interactions between these three effects, the total effect is obtained by a straightforward summation of the Direct Effect and the two Indirect Effects. $^{40}$

To get a sense of just how large is the Total Effect - and so how effective is a CA - there are two performance measures we could calculate.

First, following Davies and Ormosi (2014), we could measure the Total Effect relative to Potential Harm, $\frac{T E}{H^{0}}$. This shows how much of the potential harm the CA is removing.

Second, we could measure the Total Effect and the Indirect Effects relative to the Direct Effect that CAs think they can measure. But this involves two rather separate questions:

- how large are the indirect effects relative to the direct effect as defined above in (29) ?

- how large are the indirect effects relative to a measure of the direct effect that a CA might actually be able to calculate using data it can readily observe?

In an obvious notation the ratio of the two indirect effects to the direct effect as defined in (29), are given by:

$$
R_{I D E}=\frac{I D E}{D E}=\frac{(1-\bar{\Delta})}{\bar{\Delta} \cdot(1-\sigma)} ; \quad R_{I P E}=\frac{I P E}{D E}=\frac{\left[C S\left(p^{C}\right)-C S\left(p^{M}\right)\right]}{\bar{\Delta} \cdot(1-\sigma) \cdot\left[C S(c)-C S\left(p^{C}\right)\right]}
$$

\footnotetext{
${ }^{40}$ This contradicts the assertion by Sorgard (2015) that these interactions imply that one should not add up the three effects.
} 
We can re-write the second term on the RHS of (31) as:

$$
R_{I P E}=\frac{\Theta(\tau)}{\bar{\Delta} .(1-\sigma)}, \text { where } \Theta(\tau)=\frac{\left[C S\left(p^{C}\right)-C S\left(p^{M}\right)\right]}{\left[C S(c)-C S\left(p^{C}\right)\right]}
$$

Here $\Theta(\tau)$ is the ratio of the difference in consumer surplus under a cartel and monopoly to that between having a cartel and competition. It will be negative if the cartel price is above the monopoly price.

Now the direct effect as defined above in (29) depends on the two terms $\bar{\Delta}$ and $\sigma$ which are going to be incredibly hard for a CA to actually measure, essentially because they both depend on counterfactuals that are not directly observable:

- $\bar{\Delta}$ depends on having a view about the industries in which cartels might have arisen in the absence of a CA;

- $\sigma$ depends on the present value of profits that a cartel would have made had it stayed in existence for ever.

What a CA should be able to calculate using data that is readily observable is the number of cartels it actually investigates, penalises and stops in any given period. Within our framework this would be $\beta \gamma \bar{\Delta}$ - which a CA could observe even if it cannot observe the individual terms in this expression. If we multiply this by the gain in consumer surplus, $\left[C S(c)-C S\left(p^{C}\right)\right]$, that arises from forcing an industry to set the competitive price rather than the cartel price we get what we can call the Observable Direct Effect $(O D E)$ :

$$
O D E=\beta \gamma \bar{\Delta}\left[C S(c)-C S\left(p^{C}\right)\right]
$$

This is the exact analogue of what Davies and Ormosi (2014) call Detected Harm. So, using (29) and (31), the amount by which a CA has to scale up its Observable Direct Effect to obtain a measure of the Total Effect of its actions is:

$$
\frac{T E}{O D E}=\frac{D E}{O D E} \cdot \frac{T E}{D E}=\frac{D E}{O D E}\left(1+R_{I D E}+R_{I P E}\right),
$$

where, from (29) and (6) we have:

$$
\frac{D E}{O D E}=\frac{(1-\sigma)}{\beta \gamma}=\sigma \cdot \frac{\delta}{1-\delta \chi}
$$

What (34) brings out is that there are TWO reasons why the Total Effect of a CA's actions might differ from the Direct Effect that they can and do measure. The first, which everybody recognises and discusses, is the fact that the Direct Effect fails to capture the indirect/behavioural effects of a CA's interventions. But the second, which has not received any attention, is that the Direct Effect that CA's can measure (the Observable Direct Effect) 
may not actually be the true Direct Effect. From the expression in (35) the true Direct Effect may be either greater or less than the Observable Direct Effect. In the next section we will show that both outcomes are possible. ${ }^{41}$

\subsection{The Welfare Effects of Marginal Increases in Enforcement Parameters}

Now consider the welfare effects of small increases in the intervention parameters $\beta, \gamma$ and $\chi$. Analogously to the analysis in the previous section, we can measure these as either the marginal change in average consumer surplus as defined in (26) or, equivalently, the marginal change in harm as defined by (28). For simplicity we use the latter approach.

Differentiate (28) and we get the Total Marginal Effect (TME) of a small increase in intervention $i=\beta, \gamma, \chi$ as: ${ }^{42}$

$$
-\frac{\partial H}{\partial i}=\left\{\frac{\partial H}{\partial \sigma}\left(-\frac{\partial \sigma}{\partial i}\right)\right\}+\left\{\frac{\partial H}{\partial \bar{\Delta}}\left(-\frac{\partial \bar{\Delta}}{\partial i}\right)\right\}+\left\{\frac{\partial H}{\partial p^{C}}\left(-\frac{\partial p^{C}}{\partial i}\right)\right\},
$$

The first term on the RHS of (36) is the Marginal Direct Effect(MDE) since it shows the impact on welfare arising through the effect that a marginal increase in an intervention has on $\sigma$, taking as given the behaviour of the cartel as reflected in $\bar{\Delta}$ and $p^{C}$.

The second term on the RHS of (36) is the Marginal Indirect Deterrence Effect (MIDE), since it shows the impact on welfare arising through the effect that a marginal increase in an intervention has on $\bar{\Delta}$ - the proportion of industries in which stable cartels choose to form taking as given both $\sigma$ and $p^{C}$

The third term on the RHS of (36) is the Marginal Indirect Price Effect (MIPE) since it shows the impact on welfare arising through the effect that a marginal increase in an intervention has on $p^{C}$ - the price set by those stable cartels that do form - taking as given both $\sigma$ and $\bar{\Delta}$. From Proposition 3(iv) this will be negative if $p^{C}>p^{M}$.

So, analogous to (30), we get a simple decomposition of the total marginal effect of an intervention into a direct effect and two indirect effects:

$$
T M E=M D E+M I D E+M I P E
$$

We can re-write (36) in elasticity form:

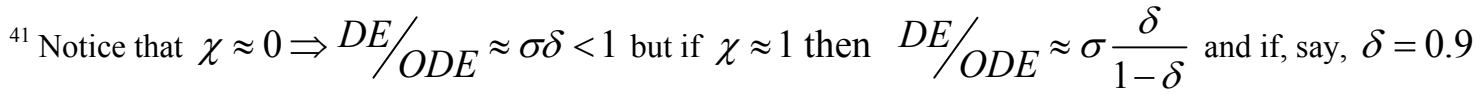
this implies $D E / O D E \approx 9 \sigma$.

${ }^{42}$ Notice that because Davies and Ormosi (2014) have no theory about how the crucial performance variables $\left(\sigma, \bar{\Delta}, p^{C}\right)$ are determined by the underlying intervention parameters they are unable to provide any analysis of these marginal effects. 


$$
\begin{aligned}
\left(-\frac{\partial H}{\partial i} \cdot \frac{i}{H}\right) & =\left\{\left(\frac{\partial H}{\partial \sigma} \cdot \frac{\sigma}{H}\right)\left(-\frac{\partial \sigma}{\partial i} \cdot \frac{i}{\sigma}\right)\right\} \\
& +\left\{\left(\frac{\partial H}{\partial \bar{\Delta}} \cdot \frac{\bar{\Delta}}{H}\right)\left(-\frac{\partial \bar{\Delta}}{\partial i} \cdot \frac{i}{\bar{\Delta}}\right)\right\} \\
& +\left\{\left(\frac{\partial H}{\partial p^{C}} \cdot \frac{p^{C}}{H}\right)\left(-\frac{\partial p^{C}}{\partial i} \cdot \frac{i}{p^{C}}\right)\right\}
\end{aligned}
$$

Now, from (25) we have:

$$
\left(\frac{\partial H}{\partial \sigma} \cdot \frac{\sigma}{H}\right)=\left(\frac{\partial H}{\partial \bar{\Delta}} \cdot \frac{\bar{\Delta}}{H}\right)=1 ; \quad\left(\frac{\partial H}{\partial p^{C}} \cdot \frac{p^{C}}{H}\right)=\frac{p^{C} Q\left(p^{C}\right)}{\left[C S(c)-C S\left(p^{C}\right)\right]}=\eta\left(p^{C}\right)
$$

Substitute this and the results in Proposition 2 (i) and Proposition 5 (iii) \& (iv) into (39) and we get;

$$
\begin{aligned}
\left(-\frac{\partial H}{\partial \beta} \cdot \frac{\beta}{H}\right) & =2\left(-\frac{\partial \sigma}{\partial \beta} \cdot \frac{\beta}{\sigma}\right)+\left(-\frac{d \bar{\Delta}^{0}(\tau)}{d \tau} \cdot \frac{\tau}{\bar{\Delta}^{0}(\tau)}\right)+\eta\left(p^{C}\right) \cdot\left(-\frac{d p^{C}}{d \tau} \cdot \frac{\tau}{p^{C}}\right) \\
& =2(1-\sigma)+\left(-\frac{d \bar{\Delta}^{0}(\tau)}{d \tau} \cdot \frac{\tau}{\bar{\Delta}^{0}(\tau)}\right)+\eta\left(p^{C}\right) \cdot\left(-\frac{d p^{C}}{d \tau} \cdot \frac{\tau}{p^{C}}\right) \\
\left(-\frac{\partial H}{\partial \gamma} \cdot \frac{\gamma}{H}\right) & =2\left(-\frac{\partial \sigma}{\partial \gamma} \cdot \frac{\gamma}{\sigma}\right)=2(1-\sigma) \\
\left(-\frac{\partial H}{\partial \chi} \cdot \frac{\chi}{H}\right) & =2\left(-\frac{\partial \sigma}{\partial \chi} \cdot \frac{\chi}{\sigma}\right)=2(1-\sigma) \frac{\delta \chi}{1-\delta \chi} \\
\left(-\frac{\partial H}{\partial \rho} \cdot \frac{\rho}{H}\right) & =\left(-\frac{d \bar{\Delta}^{0}(\tau)}{d \tau} \cdot \frac{\tau}{\bar{\Delta}^{0}(\tau)}\right)+\eta\left(p^{C}\right) \cdot\left(-\frac{d p^{C}}{d \tau} \cdot \frac{\tau}{p^{C}}\right)
\end{aligned}
$$

These various formulae reflect the fact that, as noted in Propositions 1, 2, 3 and 5, the various enforcement parameters work through different channels.

If we substitute (43) and (42) into (41) we get the following relationships between the marginal effects of the various enforcement parameters:

$$
\begin{aligned}
& \left(-\frac{\partial H}{\partial \beta} \cdot \frac{\beta}{H}\right)=\left(-\frac{\partial H}{\partial \gamma} \cdot \frac{\gamma}{H}\right)+\left(-\frac{\partial H}{\partial \rho} \cdot \frac{\rho}{H}\right) \\
& \left(-\frac{\partial H}{\partial \chi} \cdot \frac{\chi}{H}\right)=\left(-\frac{\partial H}{\partial \gamma} \cdot \frac{\gamma}{H}\right) \frac{\delta \chi}{1-\delta \chi}
\end{aligned}
$$

We then have the following proposition regarding the marginal effectiveness of the different enforcement parameters. 


\section{Proposition 6}

(i) If $\quad p^{C} \leq p^{M}$ then $\left(-\frac{\partial H}{\partial \rho} \cdot \frac{\rho}{H}\right)>0$, but if $p^{C}>p^{M}$ then

$$
\left(-\frac{\partial H}{\partial \rho} \cdot \frac{\rho}{H}\right) \frac{\geq}{<} 0 \text { as }\left(-\frac{d \bar{\Delta}^{0}(\tau)}{d \tau} \cdot \frac{\tau}{\bar{\Delta}^{0}(\tau)}\right) \frac{\geq}{<} \eta\left(p^{C}\right) \cdot\left(\frac{d p^{C}}{d \tau} \cdot \frac{\tau}{p^{C}}\right)>0 ;
$$

$$
;\left(-\frac{\partial H}{\partial \chi} \cdot \frac{\chi}{H}\right) \frac{\geq}{<}\left(-\frac{\partial H}{\partial \gamma} \cdot \frac{\gamma}{H}\right)>0 \text { as } \delta \chi \frac{\geq}{<2}
$$

$$
\left(-\frac{\partial H}{\partial \beta} \cdot \frac{\beta}{H}\right)>\left(-\frac{\partial H}{\partial \rho} \cdot \frac{\rho}{H}\right) ; \quad\left(-\frac{\partial H}{\partial \beta} \cdot \frac{\beta}{H}\right) \geq\left(-\frac{\partial H}{\partial \gamma} \cdot \frac{\gamma}{H}\right) \text { as }\left(-\frac{\partial H}{\partial \rho} \cdot \frac{\rho}{H}\right) \frac{\geq}{<} 0 .
$$

Proof: (i) if $p^{C} \leq p^{M}$ then, from Proposition 3 (iv) an increase in $\rho$ does not raise the cartel price, so every term on the RHS of (43) is non-negative and the second is strictly positive. However if $p^{C}>p^{M}$ then from Proposition 3 (iv) an increase in $\rho$ raises the cartel price, so the final term on the RHS of (43) is negative, and so an increase in the penalty rate, $\rho$, will reduce harm if the deterrence effect it has via $\bar{\Delta}^{0}$ outweighs the negative price effect. (ii) and (ii) are direct implication of equation (44).

So we have the following results based on the analysis of welfare effects of marginal increases in enforcement parameters:

- It follows directly from comparison of (41) and (43) that an increase in the probability of detection is always more effective than increasing the penalty rate;

- By comparing (41) and the first expression in (42) we conclude that provided an increase in the penalty rate reduces harm, an increase in the probability of detection also has a bigger effect than increasing the probability that successful conviction stops cartels;

- Comparison of expressions in (42) implies that increasing the effectiveness of keeping industries competitive can have a more powerful effect than increasing the probability of stopping cartels when the CA is already pretty effective at keeping industries competitive, i.e. when $\delta \chi>1 / 2$.

\section{Illustrative Calculations of the Direct and Indirect Effects}

As discussed above, the framework indicates that the direct and indirect deterrence effects are going to be extremely hard to measure in any direct way, since both $\sigma$ and $\bar{\Delta}$ are defined in relation to counterfactuals that relate to what would have happened in the absence of a CA.

So one approach to trying to calculate the various direct and indirect effects in relation to what a CA might actually be able to measure is to use whatever empirical evidence is available to calibrate the model's parameters, and then use the formulae in Section 2 to calculate the three performance variables $\sigma, \bar{\Delta}, p^{C}$ and hence the formulae in Section 4 to 
calculate all our various measures of the effectiveness of a CA. In this section we take a very preliminary step in this direction. Our aim is not to provide an exhaustive analysis of how the various direct and indirect effects vary with the underlying parameters, but rather to show that this approach is feasible and to get a feel for the parameters to which our conclusions seems most sensitive.

The model is based on parameters: $\beta, \gamma, \chi, \delta, \rho, c$, and on the two functions $Q(p)$ and $B(p)$.

To begin, it is helpful to think about the length of the period on which the model is built. The model is based on the assumption that a CA can carry out a successful cartel investigation in a period. For hard-core cartels it would be reasonable to assume that such an investigation might be successfully concluded in one year. While our model does not relate solely to hardcore cartels we will nevertheless assume that the appropriate interpretation of a period is a year.

With this in mind we discuss in turn the calibration of our various parameters. We begin with the four enforcement parameters, $\beta, \gamma, \chi$ and $\rho$.

$\beta$ : In their analysis Davies and Ormosi (2014), cite empirical evidence that the probability of detection ranges from 0.1 to 0.33 , and assume a uniform distribution between these bounds. So we will report results for the three values $\beta=0.1,0.2,0.3$. However, following the work of Bryant and Eckart (1991), a widely used value is $\beta=0.15$. We have undertaken calculations for this value of $\beta$ as well. Obviously the resulting values for all our various measures of CA effectiveness lie between those obtained for $\beta=0.1$ and $\beta=0.2$, though, given the non-linearity of our performance variables such as $\sigma$, they do not lie exactly half way between, though a straightforward interpolation will give a good approximation. ${ }^{43}$

$\gamma$ : As noted above, Harrington $(2004,2005)$ and Davies and Ormosi (2014) effectively assume that $\gamma=1$. So, to facilitate comparison with their analysis, we will also allow $\gamma$ to take the value $\gamma=1$. However, our framework allows us to test the sensitivity of the conclusions to this implicit assumption, so we also examine how our results change if $\gamma=0.8$.

$\chi$ : As noted above, it is implausible to assume that CAs have the resources to continuously monitor industries after a successful intervention. Moreover, both Davies and Ormosi (2009) and Connor (2015) cite evidence that cartels do indeed re-emerge in industries following CA interventions. So it is implausible that $\chi=1$. However, as suggested above, one interpretation of what Davies and Ormosi (2014) mean by removing harm is that they are talking about permanent removal. So to understand what might be driving their conclusions we want to allow the possibility that $\chi$ can be quite large. Accordingly we will undertake calculations for the three values of $\chi=0.1,0.5,0.9$.

\footnotetext{
${ }^{43}$ Precise figures available from the authors on request.
} 
$\rho$ : We assume throughout that penalties are based on revenue and that neither the penalty rate nor the probability of detection depend on the cartel price. In line with rates that apply in countries that use revenue as the penalty base for the bulk of our analysis we assume a $10 \%$ penalty - i.e. $\rho=0.1$. However in order to address the question posed by CAs in the quotation at the start of the paper about how the effectiveness of interventions depends on "differences in competition policy enforcement" we discuss how our conclusions are affected if, instead, $\rho=0.2$. Given our assumptions about the penalty structure, the cartel price will be above the monopoly price and so both the absolute and marginal indirect price effects will be negative.

Our framework also depends on a number of model parameters:

c: We normalise prices by assuming that the competitive price $c=1$.

Consistent with this we assume that the demand function is $Q(p)=1+\varepsilon-p^{44}$ where $\varepsilon=-\frac{d p}{d Q} \cdot \frac{Q}{p}>0$ is the inverse price elasticity evaluated at the competitive price. Connor and Lande (2012) suggest that the elasticity of demand lies in the range 0.95 to 1.65 with an average value of 1.3 , which would imply values for $\varepsilon$ of $1.05,0.61$ and 0.77 respectively. In what follows we allow $\varepsilon$ to take the three values $\varepsilon=1.0,0.8,0.6$. However it turns out that our results are not very sensitive to $\varepsilon$, so in this section of the paper we report results just for the case $\varepsilon=0.8$.

$\delta$ : The discount rate, $\delta$, is both the rate at which cartels discount future profits and the rate at which CAs discount future consumer surplus. There is little agreement on what value this should take, with a wide variety of values being used in different studies. ${ }^{45}$ We use $\delta=0.9$ as the central value in our calculations. However we report how our conclusions are affected if, instead, $\delta$ takes a range of other values between $\delta=0.8$ and $\delta=0.98 .^{46}$

The Appendix gives more details of the formulae used in the calculations given the functional forms described above and a full list of the resulting calculations, including the sensitivity of the conclusions presented here to the assumed value of the penalty rate $(\rho=0.1)$ and to the model parameters $\delta, \varepsilon$.

\footnotetext{
${ }^{44}$ Given the assumptions made above about the penalty base, this implies $B(p)=p(1+\varepsilon-p)$.

${ }^{45}$ As is well known the value of this parameter will in practice be affected by considerations such as the frequency of interaction between cartel members and the evolution of demand, that will vary widely across industries, and from which we abstract here. We also performed a sensitivity analysis with respect to discount factor and other parameters of the model. The detailed results on sensitivity analysis are available from authors upon request.

${ }^{46}$ We have performed several sensitivity checks with respect to discount factor. For a range of discount factors between $\delta=0.8$ and $\delta=0.98$ additional numerical simulations presented in the Appendix show that most of the effects are monotonic in $\delta$. Namely, $\bar{\Delta}$ and ODE are decreasing in $\delta$. On the other hand, TE, TE/ $\mathrm{H}^{0}$, and $\mathrm{TE} / \mathrm{ODE}$ are increasing in $\delta$. TE/ODE ratio ranges between 2 and 13 for the range of discount factors and other parameters we consider. Note also that RIDE is non-monotonic in $\delta$.
} 


\subsection{The Total Effects of a Competition Authority's Interventions.}

We start by considering how good a job a competition authority does in removing some of the potential harm that would have existed had there been no authority in existence. This is measured by $T E / H^{0}$ and Table 1 sets out the values for this that emerge from our framework. $^{47}$

Table 1:TE/ $H^{0}$

$$
\delta=0.9, \varepsilon=0.8, \rho=0.1
$$

\begin{tabular}{|c|c|c|c|c|c|c|c|}
\hline \multirow[b]{2}{*}{$\mathbf{X}$} & \multirow{2}{*}{$\gamma$} & \multicolumn{3}{|c|}{1} & \multicolumn{3}{|c|}{0.8} \\
\hline & & 0.1 & 0.2 & 0.3 & 0.1 & 0.2 & 0.3 \\
\hline \multicolumn{2}{|c|}{0.9} & 0.552 & 0.751 & 0.843 & 0.488 & 0.694 & 0.799 \\
\hline \multicolumn{2}{|c|}{0.5} & 0.281 & 0.463 & 0.587 & 0.239 & 0.405 & 0.527 \\
\hline \multicolumn{2}{|c|}{0.1} & 0.194 & 0.341 & 0.454 & 0.164 & 0.296 & 0.401 \\
\hline
\end{tabular}

If we look at the left hand side of the table, where $\gamma=1$ and the top row, where $\chi=0.9$ and so the set-up is effectively that which is implicitly assumed by Davies and Ormosi (2014) then we see that as the amount of effort that CAs put into investigations varies from a low value of $\beta=0.1$ to the high value of $\beta=0.3$ then the fraction of harm removed increases from $55.2 \%$ to $84.3 \%$ with the intermediate value of $75 \%$ when $\beta=0.2$. These are almost exactly the figures produced in Table 2 of Davies and Ormosi (2014) where the results are, $55.5 \%, 86.9 \%$ and $76.7 \%$ respectively.

However the table also brings out just how sensitive these figures are to the implicit assumptions. So, for example, if the probability of keeping an industry competitive, $\chi$, drops from $90 \%$ to $50 \%$ then the fraction of potential harm removed by a CA varies from $28.1 \%$ to $58.7 \%$ with an intermediate value of $46.3 \%$. So they have almost halved.

Comparing the LHS of Table 1 with the RHS we see that lowering the proportion of detected cartels that are immediately stopped, $\gamma$, from $100 \%$ to $80 \%$ also reduces the amount of potential harm removed by a Competition Authority.

So we have:

Result 1: While our framework can support the finding of Davies and Ormosi (2014) that the fraction of harm removed by a CA can vary from $55 \%$ to $85 \%$ depending on the probability of detection, it also shows that this conclusion is at the top end of the range and is very sensitive to (implicit) assumptions about the other key intervention parameters, $\gamma$ and $\chi$.

\footnotetext{
${ }^{47} \mathrm{We}$ are grateful to Khadija Lateef, an undergraduate student of Economics at the University of St Andrews for research assistance in undertaking the computations in this section.
} 
The other aspect of CA performance is that CAs want to understand how large is the Total Effect of their interventions relative to the direct effect that they can measure - what we call the Observable Direct Effect. That is they want to understand how large is TE/ODE, but also how is this attributed to the indirect deterrence effect and the indirect price effect. From equation (34) we know that the magnitude of $T E / O D E$ depends on three other terms: how large are the Indirect Deterrence and Indirect Price Effects relative to the "true" Direct Effect (RIDE and RIPE, respectively), and how large is $D E / O D E$ - the ratio of the "true" Direct Effect to the Observable Direct Effect (Davies and Ormosi's Detected Harm).

Table 2 sets out the answers to these questions by presenting figures for $T E / O D E$ followed by its three components RIDE, RIPE and DE / ODE. Once again all these calculations have been performed assuming $\delta=0.9, \varepsilon=0.8, \rho=0.1$.

Table 2a: $T E / O D E$

\begin{tabular}{|c||c||c|c|c|c|c|c|}
\hline \multicolumn{1}{|c||}{$\boldsymbol{X}$} & $\boldsymbol{\gamma}$ & \multicolumn{3}{c|}{1} & \multicolumn{3}{c|}{0.8} \\
\cline { 2 - 8 } & $\boldsymbol{\beta}$ & 0.1 & 0.2 & 0.3 & 0.1 & 0.2 & 0.3 \\
\hline \hline 0.9 & 8.359 & 7.729 & 7.416 & 8.649 & 8.063 & 7.751 \\
\hline 0.5 & 3.365 & 3.251 & 3.179 & 3.475 & 3.386 & 3.331 \\
\hline 0.1 & 2.193 & 2.159 & 2.139 & 2.279 & 2.259 & 2.250 \\
\hline
\end{tabular}

Table 2b: $R I D E=I D E / D E$

\begin{tabular}{|c||c||c|c|c|c|c|c|}
\hline \multirow{2}{*}{$\mathbf{X}$} & $\boldsymbol{\gamma}$ & \multicolumn{3}{c|}{1} & \multicolumn{3}{c|}{0.8} \\
\cline { 2 - 8 } & $\boldsymbol{\beta}$ & 0.1 & 0.2 & 0.3 & 0.1 & 0.2 & 0.3 \\
\hline \hline 0.9 & 1.639 & 2.246 & 2.898 & 1.560 & 2.062 & 2.601 \\
\hline 0.5 & 1.462 & 1.728 & 2.014 & 1.484 & 1.715 & 1.963 \\
\hline 0.1 & 1.540 & 1.738 & 1.951 & 1.610 & 1.790 & 1.982 \\
\hline
\end{tabular}

Table 2c: $R I P E=I P E / D E$

\begin{tabular}{|c||c||c|c|c|c|c|c|}
\hline \multirow{2}{*}{$\mathbf{X}$} & $\boldsymbol{\gamma}$ & \multicolumn{3}{|c|}{1} & \multicolumn{3}{c|}{0.8} \\
\cline { 2 - 8 } & $\boldsymbol{\beta}$ & 0.1 & 0.2 & 0.3 & 0.1 & 0.2 & 0.3 \\
\hline \hline 0.9 & -0.039 & -0.068 & -0.107 & -0.042 & -0.070 & -0.104 \\
\hline 0.5 & -0.070 & -0.092 & -0.117 & -0.082 & -0.104 & -0.128 \\
\hline 0.1 & -0.103 & -0.124 & -0.147 & -0.124 & -0.145 & -0.167 \\
\hline
\end{tabular}

Table 2d: $D E / O D E$

\begin{tabular}{|c||c||c|c|c|c|c|c|}
\hline \multirow{2}{*}{$\mathbf{X}$} & $\boldsymbol{\gamma}$ & \multicolumn{3}{|c|}{1} & \multicolumn{3}{|c|}{0.8} \\
\cline { 2 - 8 } & $\boldsymbol{\beta}$ & 0.1 & 0.2 & 0.3 & 0.1 & 0.2 & 0.3 \\
\hline \hline 0.9 & 3.210 & 2.432 & 1.957 & 3.435 & 2.695 & 2.217 \\
\hline 0.5 & 1.410 & 1.233 & 1.098 & 1.447 & 1.297 & 1.175 \\
\hline 0.1 & 0.900 & 0.826 & 0.763 & 0.916 & 0.854 & 0.799 \\
\hline
\end{tabular}


One general conclusion that emerges from this is that although the indirect price effect is negative its absolute magnitude is small and doesn't contribute much to our understanding of what drives the link between the Total Effect of a CA's interventions and the Observable Direct Effect $(O D E)$ that CAs can measure. So, in the discussion that follows we will say no more about it. The important effects that are at work are: the unobserved deterrence effect that everyone recognises and discusses, but also a second factor that has so far received no attention - the fact that the Observable Direct Effect significantly mis-measures the "true" Direct Effect.

If we start once again with the situation that is closest to that implicitly assumed by Davies and Ormosi (2014) - i.e. where $\gamma=1, \chi=0.9$ - then we see from the first row on the LHS of Table 2a the total effect of a CA's interventions may be between 7.5 and 8.5 times greater than the Observable Direct Effect. This is in part because the neglect of the Indirect Deterrence Effect, which, from Table $2 \mathrm{~b}$ can vary between 1.6 and 2.9 times the Direct Effect, but also because of the neglect of the fact that the "true" Direct Effect varies from 1.9 to 3.2 times the Observable Direct Effect. ${ }^{48}$ However, once again, these conclusions are very sensitive to what we assume about the parameter values - particularly the probability of keeping the industry competitive, $\chi$ - where the Total Effect will be just over twice as large as the Observed Direct Effect when $\chi=0.1$. But this sensitivity is largely driven by the fact that the ratio of the true Direct Effect to the Observable Direct Effect is very sensitive to the assumed value of $\chi$ - see footnote 30 above. On the other hand the conclusions are not terribly sensitive to variations in either $\beta$ or $\gamma$.

Our figures are lower than those reported in Davies and Ormosi (2014), Table 1 even in their case where, as here, the probability of detection is constant. For they report that the Total Harm is 13.0 times the Detected Harm, while Deterred Harm is 7.8 times Detected Harm. So clearly the differences in methodology do matter when trying to put a figure on these important ratios.

We summarise our findings in:

\section{Result 2:}

(i) The Total Effect is around 8 times as large as the Observable Direct Effect when $\chi=0.9$ but this drops to just over 3 when $\chi=0.5$ and just over 2 when $\chi=0.1$.

(ii) There are two important effects at work:

a. the unmeasured Indirect Deterrence Effect which is between 1.5 and 2.9 times as large as the Direct Effect depending on the various parameter values;

b. the fact that the true Direct Effect differs significantly from the Observable Direct Effect,

(iii) the ratio of the true Direct Effect to the Observable Direct Effect is very sensitive to the assumed value of $\chi$, taking values around 2 to 3 when $\chi=0.9$, but just 0.75 to 0.9 when $\chi=0.1$.

\footnotetext{
${ }^{48}$ Taken together these imply that the Indirect Deterrence Effect is around 5.3 to 5.4 times as large as the Observable Direct Effect
} 
(iv) Because we have assumed that penalties are based on revenue and that both the probability of detection and the penalty rate are independent of the cartel price, the Indirect Price Effect is negative (as theory predicts), but our results show that it is very small in absolute magnitude.

\subsubsection{Sensitivity to Model Parameters}

We have undertaken calculations of how the measured values of the deterrence and total effects of a CA's interventions vary with the two key model parameters, $\varepsilon$ and $\delta$. The Appendix shows how the values of $\bar{\Delta}, R I D E, T E / H^{0}$ and $T E / O D E$ that we presented above vary as we allow each of the two model parameters to vary over the ranges specified above.

We conclude that the results are not very sensitive to the assumed values of the inverse elasticity of demand, $\varepsilon$. However, given the dynamic nature of our framework where we examine the way in which current interventions affect future behaviour of cartels, it is perhaps unsurprising that our conclusions are rather sensitive to the assumed value of the discount factor, $\delta$. So for example, we reported above that, when $\gamma=1$ and $\chi=0.9$ then the fraction of potential harm removed, $T E / H^{0}$ varies from $55 \%$ through $75 \%$ to $85 \%$ as the probability of successful prosecution, $\beta$, varies from 0.1 through 0.2 to 0.3 . However, these fractions rise to $71 \%, 87 \%$ and $93 \%$ respectively when $\delta=0.98$, and fall to $41 \%, 62 \%$ and $73 \%$ respectively when $\delta=0.8$. Similarly the values reported above for the ratio of the Total Effect to the Observable Direct Effect, TE/ODE, were 8.4, 7.7 and 7.4 respectively. These values rise to $13.3,12.2$ and 11.7 respectively when $\delta=0.98$, and fall to 5.5, 5.1 and 5.0 when $\delta=0.8$.

So we see that considerable thought needs to be given to the appropriate choice of discount rate when placing numerical values on various measures of the total effectiveness of CA interventions.

\subsubsection{Sensitivity to Penalty Rate}

As indicated above Competition Authorities would like to know how the effectiveness of their interventions varies "depending on differences in competition policy enforcement." To address this question we keep our model parameters at their central values: $\delta=0.9, \quad \varepsilon=0.8$ but now allow the penalty rate to take the value $\rho=0.2$. We know from the theory that an increase in the penalty rate will:

- have no effect on $\sigma$;

- since $\frac{d \bar{\Delta}^{0}(\tau)}{d \tau}<0$ it will improve deterrence;

- it will cause cartels to increase the price. 
Since the indirect price effects are typically very small we expect this latter effect to be dominated by the second.

We report below how the values for $T E / H^{0}$ and for $T E / O D E$ that we presented above in Tables 1 and 2 a respectively change when we use this new value of the penalty rate.

Table 1': $T E / H^{0}, \delta=0.9, \varepsilon=0.8, \rho=0.2$

\begin{tabular}{|c||c||c|c|c|c|c|c|}
\hline \multirow{3}{*}{$\chi$} & $\boldsymbol{\gamma}$ & \multicolumn{3}{|c|}{1} & \multicolumn{3}{c|}{0.8} \\
\cline { 2 - 8 } & $\boldsymbol{\beta}$ & 0.1 & 0.2 & 0.3 & 0.1 & 0.2 & 0.3 \\
\hline \hline 0.9 & 0.565 & 0.765 & 0.858 & 0.503 & 0.712 & 0.818 \\
\hline 0.5 & 0.302 & 0.495 & 0.626 & 0.261 & 0.441 & 0.571 \\
\hline 0.1 & 0.217 & 0.380 & 0.505 & 0.188 & 0.337 & 0.457 \\
\hline
\end{tabular}

Table 2a: $T E / O D E, \delta=0.9, \varepsilon=0.8, \rho=0.2$

\begin{tabular}{|c||c||c|c|c|c|c|c|}
\hline \multirow{2}{*}{$\mathbf{X}$} & $\boldsymbol{\gamma}$ & \multicolumn{3}{|c|}{1} & \multicolumn{3}{c|}{0.8} \\
\cline { 2 - 8 } & $\boldsymbol{\beta}$ & 0.1 & 0.2 & 0.3 & 0.1 & 0.2 & 0.3 \\
\hline \hline 0.9 & & 8.798 & 8.378 & 8.322 & 9.163 & 8.796 & 8.750 \\
\hline 0.5 & 3.711 & 3.693 & 3.737 & 3.896 & 3.912 & 3.982 \\
\hline 0.1 & 2.521 & 2.558 & 2.624 & 2.681 & 2.742 & 2.829 \\
\hline
\end{tabular}

As we can see and as both ratios $T E / H^{0}$ and $T E / O D E$ are indeed increasing in $\rho$, though, particularly for $T E / H^{0}$, the effect is quite small.

\subsection{The Marginal Welfare Effects of a Competition Authority's Interventions}

As reported in Section 4 - particularly in equations (41)-(44) - the four enforcement parameters work through very different channels. As a consequence the magnitudes of the various marginal effects depend on rather different parameters. So, from (42), the marginal effect of an increase in $\gamma$ depends solely on $\sigma$, while the marginal effect of an increase in $\chi$ depends additionally on the associated value of $\chi$. However the marginal effects of an increase in the penalty rate, $\rho$, depend on the values of $\varepsilon, \beta$ and $\rho$, since these last two parameters determine $\tau$. From (44) the marginal effect of an increase in $\beta$ therefore depends on $\sigma, \varepsilon, \beta$ and $\rho$.

Now, from Table A1 in the Appendix we find that if we set our 3 intervention parameters $(\beta, \gamma, \chi)$ to their maximum assumed values - namely $(0.3,1.0,0.9)$ - then the associated value of $\sigma$ is 0.413 ; while if we set them to their minimum assumed values - namely $(0.1,0.8,0.1)$ - then the associated value of $\sigma$ is 0.927 . If we set the values of $\beta$ and $\chi$ to their intermediate values of 0.2 and 0.5 respectively, and set $\gamma=1$ we get the intermediate value of $\sigma=0.753$. Since the values of the associated intervention parameters are therefore uniquely associated with each of these three values of $\sigma$, in what follows we will report the 
results by referring solely to the value of $\sigma$. We have also used the central values for the remaining parameters - i.e. we have set $\delta=0.9, \rho=0.1, \varepsilon=0.8$.

Table 3: Marginal Effects

\begin{tabular}{|c||c|c|c|c|}
\hline$\sigma$ & $\left(-\frac{\partial H}{\partial \beta} \cdot \frac{\beta}{H}\right)$ & $\left(-\frac{\partial H}{\partial \gamma} \cdot \frac{\gamma}{H}\right)$ & $\left(-\frac{\partial H}{\partial \chi} \cdot \frac{\chi}{H}\right)$ & $\left(-\frac{\partial H}{\partial \rho} \cdot \frac{\rho}{H}\right)$ \\
\hline \hline 0.413 & 1.263 & 1.174 & 5.005 & 0.089 \\
\hline 0.753 & 0.557 & 0.494 & 0.404 & 0.057 \\
\hline 0.927 & 0.174 & 0.146 & 0.014 & 0.028 \\
\hline
\end{tabular}

In the Appendix we report how these different marginal effects decompose into their associated Direct Effects and Indirect Deterrence and Price Effects. So we have:

Result 3 For the range of parameter values considered here:

(i) For all four enforcement parameters the elasticities relating to their total effect are smaller than 1;

(ii) Increasing the probability of successful investigation, $\beta$, has a more powerful impact than increasing the probability of closing cartels down following an investigation, $\gamma$;

(iii) The effectiveness of raising the probability of keeping an industry competitive once a cartel has been shut down, $\chi$, rises sharply with the value of $\chi$ itself.

(iv) Because it generates no direct effect, increasing the penalty rate has an effectiveness that is between $1 / 14^{\text {th }}$ and $1 / 6^{\text {th }}$ of that of increasing the probability of successful detection.

To summarize we can conclude that on average the marginal effect of an increase in the penalty rate is around ten times smaller than the marginal effect of an increase in the probability of successful prosecution. Secondly, potentially the most powerful marginal effect is that of longer-term interventions aiming at preventing recidivism - but this is very sensitive to the existing level of recidivism and to the toughness of antitrust enforcement (i.e. the level of probability of successful prosecution and the amount of the resources the CA puts in preventing recidivism both in the short and in the long term). For example, for the case with the strongest (toughest) CA (see the first row in Table 3), marginal effect of long-term interventions aiming at preventing recidivism (i.e. $\chi$ ) can be about 5 times higher than the marginal effects of other two interventions. However, for the weakest CA (see the last row in Table 3), marginal effect of $\chi$ is smaller than the marginal effects of other interventions.

\section{Concluding Remarks}

We have presented a model of cartel formation capturing the process of the birth and death of cartels that allows an explicit characterization of the effects on welfare of a wide range of policy instruments. We distinguish between a direct effect of detecting and stopping cartels, 
as well as an indirect-deterrence effect of reducing the cartel rate (i.e. the fraction of cartels out of those that would exist in the absence of a CA that exist in its presence and given its enforcement activities) and an indirect-price effect or effect on the price set by the cartels that form. We have used this model to obtain a number of Propositions through which we characterize the total welfare effect of the presence of a competition authority and the marginal effects of the various enforcement interventions.

Though our contribution has related concerns and objectives to that of Davies and Ormosi (2014), their conceptual framework and modeling approach is very different to the one presented above. While some of our numerical results are very similar to theirs, others are significantly different, so the difference in methodologies really matters.

Although our framework is very rich, there are a number of extensions that can be made. So, for example, our numerical simulations are based on the assumption that, while the penalty is based on revenue, both the penalty rate and the probability of detection are independent of the cartel price. As shown in Katsoulacos and Ulph (2013), if either of these are an increasing function of the cartel price then the cartel price will be lower than that used in the simulations. That could produce not just a positive indirect price effect but also a stronger deterrent effect. It would be fairly straightforward to undertake an extension to capture this possibility. 


\section{Appendix}

\section{A1. $\quad$ Basic Setup}

As explained in the text, the model is based on parameters: $\beta, \gamma, \chi, \delta, \rho, c$, and on the two functions $Q(p)$ and $B(p)$. We make the following assumptions regarding these.

(a) Enforcement Parameters

$\beta$ : This takes the 3 values: $\beta=0.1, \quad 0.2, \quad 0.3$.

$\gamma$ : This takes the 2 values: $\gamma=1.0,0.8$.

$\chi$ : This takes the 3 values: $\chi=0.1,0.5,0.9$.

$\rho$ : We assume that penalties are based on revenue and that neither the penalty rate nor the probability of detection depend on the cartel price. In this Appendix we use the single value: $\rho=0.1$, which implies that $\tau=\beta \rho$ takes the 3 values: $\tau=0.01,0.02,0.03$. However to address the question of how the total effects of a CA's interventions depend on the enforcement regime we have undertaken calculations for the case where $\rho=0.2$. These are reported in the text.

(b) Model Parameters

c: We normalise prices by assuming that the competitive price $c=1$. Consistent with this latter assumption we assume that the demand function is $Q(p)=1+\varepsilon-p$ and that consequently the penalty base is $R(p)=p(1+\varepsilon-p)$. We use $\varepsilon=0.8$ as the central value of the inverse demand elasticity parameter, but test the sensitivity of our measures of the total effectiveness of a CA's interventions to this parameter by letting $\varepsilon$ range across $\varepsilon=0.6,0.8,1.0$

$\delta$ : We use $\delta=0.9$ as our central value for the discount factor. However to test the sensitivity of our measures of the total effectiveness of a CA's interventions to this parameter, we let $\delta$ range across $\delta=0.8,0.85,0.9,0.95,0.98$.

From KMU (2015) we know that, given our assumptions above about the demand function and the penalty base, the cartel price and the fraction of industries in which cartels would form if they were never disrupted are:

$$
p^{C}(\tau)=p^{M}\left(\frac{c}{1-\tau}\right) ; \quad \bar{\Delta}^{0}(\tau)=(1-\tau) \frac{\pi^{M}\left(\frac{c}{1-\tau}\right)}{\pi^{M}(c)}<(1-\tau) .
$$

Given our assumptions about the form of the demand function, the various formulae relevant to our calculations are: 


$$
\begin{aligned}
& \bar{\Delta}^{0}(\tau)=(1-\tau)\left(1-\frac{\tau}{\varepsilon(1-\tau)}\right)^{2} ;-\frac{d \bar{\Delta}^{0}(\tau)}{d \tau} \cdot \frac{\tau}{\bar{\Delta}^{0}(\tau)}=\frac{\tau}{1-\tau}\left[1+\frac{2}{(\varepsilon(1-\tau)-\tau)}\right]>0 ; \\
& p^{C}=\frac{1+\frac{1}{1-\tau}+\varepsilon}{2} ; \quad \frac{d p^{C}}{d \tau} \frac{\tau}{p^{C}}=-\frac{\tau}{(1-\tau)[(1+\varepsilon)(1-\tau)+1]}>0 \\
& C S(c)=\frac{\varepsilon^{2}}{2} ; \quad p^{M}=1+\frac{\varepsilon}{2} ; \quad C S\left(p^{M}\right)=\frac{\varepsilon^{2}}{8} ; \quad C S\left(p^{C}\right)=\frac{\varepsilon^{2}}{8}\left(1-\frac{\tau}{\varepsilon(1-\tau)}\right)^{2} \\
& \Theta(\tau)=\frac{\left[C S\left(p^{C}\right)-C S\left(p^{M}\right)\right]}{\left[C S(c)-C S\left(p^{C}\right)\right]}=-\frac{1}{3} \cdot \frac{\tau}{\varepsilon(1-\tau)} \cdot\left(2-\frac{\tau}{\varepsilon(1-\tau)}\right) ; \\
& Q\left(p^{C}\right)=\frac{\varepsilon}{2}\left(1-\frac{\tau}{\varepsilon(1-\tau)}\right) ; \quad \eta\left(p^{C}\right)=\frac{2[(1+\varepsilon)(1-\tau)+1][\varepsilon(1-\tau)-\tau]}{[\varepsilon(1-\tau)+\tau][3 \varepsilon(1-\tau)-\tau]}
\end{aligned}
$$

\section{A2. Calculating the Total Effect of CA Interventions}

Throughout this section we set a key enforcement parameter - the penalty rate - to $\rho=0.1$.

We begin by using equation (6) in the text to calculate the value of $\sigma$ for the various values of the intervention parameters $\beta, \gamma$ and $\chi$ specified above. These are given in Table A1 below.

Table A1: $\sigma$

$$
\delta=0.9
$$

\begin{tabular}{|c||c||c|c|c|c|c|c|}
\hline \multicolumn{1}{|c||}{} & \multicolumn{1}{c||}{$\gamma$} & \multicolumn{3}{c|}{1} & \multicolumn{3}{c|}{0.8} \\
\cline { 2 - 8 }$\chi$ & $\beta$ & 0.1 & 0.2 & 0.3 & 0.1 & 0.2 & 0.3 \\
\hline \hline 0.9 & 0.679 & 0.514 & 0.413 & 0.725 & 0.569 & 0.468 \\
\hline 0.5 & 0.859 & 0.753 & 0.671 & 0.884 & 0.793 & 0.718 \\
\hline 0.1 & 0.910 & 0.835 & 0.771 & 0.927 & 0.863 & 0.808 \\
\hline
\end{tabular}

From this and equation (35) we can immediately calculate the ratio of the "true" Direct Effect to the Observable Direct Effect.

Table A2: $D E / O D E$

$$
\delta=0.9
$$

\begin{tabular}{|c||c||c|c|c|c|c|c|}
\hline \multicolumn{1}{|c||}{} & \multicolumn{1}{c||}{$\gamma$} & \multicolumn{3}{c|}{1} & \multicolumn{3}{c|}{0.8} \\
\cline { 2 - 8 }$\chi$ & $\beta$ & 0.1 & 0.2 & 0.3 & 0.1 & 0.2 & 0.3 \\
\hline \hline 0.9 & 3.210 & 2.430 & 1.957 & 3.438 & 2.694 & 2.217 \\
\hline 0.5 & & 1.410 & 1.235 & 1.097 & 1.450 & 1.294 & 1.175 \\
\hline 0.1 & & 0.900 & 0.825 & 0.763 & 0.912 & 0.856 & 0.800 \\
\hline
\end{tabular}


Notice also from equations in (A2) above that the expressions for consumer surplus under both competition and monopoly - and hence the value of potential harm $H^{0}$, which is the difference between these - depend solely on the inverse elasticity, $\varepsilon$. The values of these variables are given in Table A3 below.

Table A3: Potential Harm

\begin{tabular}{|c||c|c|c|}
\hline$\varepsilon$ & 0.6 & 0.8 & 1.0 \\
\hline \hline$C S(c)$ & 0.180 & 0.320 & 1 \\
\hline$C S\left(p^{M}\right)$ & 0.045 & 0.08 & 0.125 \\
\hline$H^{0}$ & 0.135 & 0.240 & 0.375 \\
\hline
\end{tabular}

The remaining calculations that appear in the text depend on the values of the three intervention parameters $\beta, \gamma, \chi$, the inverse elasticity of demand, $\varepsilon$, and the discount rate, $\delta$.

We begin by testing the sensitivity of our measures of the total effectiveness of a CA's interventions to the value of the model parameter, $\varepsilon$, by setting the discount rate to its central value $\delta=0.9$ and letting $\varepsilon$ range over the three values $\varepsilon=0.6,0.8,1.0$.

Table A4 sets out the values for $\bar{\Delta}$ - the fraction of those industries in which cartels would have formed in the absence of a CA in which they also form given the presence on an active $\mathrm{CA}$ - and for $T E / H^{0}$ - the fraction of potential harm removed by the competition authority. Table A5 sets out the values of RIDE - the ratio of the Indirect Deterrence Effect of a CA's interventions to their Direct Effect - and for TE/ODE - the ratio of the Total Effect to the Observable Direct Effect. As reported in the text, RIPE - the ratio of the Indirect Price Effect of a CA's interventions to their Direct Effect - is negative, but very small in absolute value, so, to avoid having tables with too many figures to digest we have not included figures for this in Table A5. They are available from the authors on request. 
Table A4: Sensitivity of $\bar{\Delta}$ and $T E / H^{0}$ to $\varepsilon$

$$
\delta=0.9, \quad \rho=0.1
$$

\begin{tabular}{|c|c|c|c|c|c|c|c|c|}
\hline & & \multirow[b]{2}{*}{$\varepsilon$} & \multicolumn{3}{|c|}{$\bar{\Delta}$} & \multicolumn{3}{|c|}{$T E / H^{0}$} \\
\hline & & & 0.6 & 0.8 & 1.0 & 0.6 & 0.8 & 1.0 \\
\hline$\gamma$ & $\beta$ & $\chi$ & & & & & & \\
\hline \multirow{9}{*}{1} & \multirow{3}{*}{0.1} & 0.9 & 0.649 & 0.655 & 0.658 & 0.555 & 0.552 & 0.550 \\
\hline & & 0.5 & 0.822 & 0.829 & 0.834 & 0.286 & 0.281 & 0.279 \\
\hline & & 0.1 & 0.871 & 0.878 & 0.883 & 0.199 & 0.194 & 0.191 \\
\hline & \multirow{3}{*}{0.2} & 0.9 & 0.470 & 0.478 & 0.483 & 0.754 & 0.751 & 0.749 \\
\hline & & 0.5 & 0.689 & 0.701 & 0.708 & 0.470 & 0.463 & 0.459 \\
\hline & & 0.1 & 0.764 & 0.777 & 0.785 & 0.349 & 0.341 & 0.336 \\
\hline & \multirow{3}{*}{0.3} & 0.9 & 0.360 & 0.370 & 0.376 & 0.846 & 0.843 & 0.842 \\
\hline & & 0.5 & 0.585 & 0.602 & 0.611 & 0.595 & 0.587 & 0.582 \\
\hline & & 0.1 & 0.673 & 0.691 & 0.702 & 0.465 & 0.454 & 0.448 \\
\hline \multirow{9}{*}{0.8} & \multirow{3}{*}{0.1} & 0.9 & 0.694 & 0.700 & 0.703 & 0.491 & 0.488 & 0.486 \\
\hline & & 0.5 & 0.846 & 0.853 & 0.858 & 0.244 & 0.239 & 0.237 \\
\hline & & 0.1 & 0.887 & 0.895 & 0.899 & 0.169 & 0.164 & 0.161 \\
\hline & \multirow{3}{*}{0.2} & 0.9 & 0.520 & 0.530 & 0.535 & 0.698 & 0.694 & 0.692 \\
\hline & & 0.5 & 0.725 & 0.738 & 0.746 & 0.413 & 0.405 & 0.401 \\
\hline & & 0.1 & 0.789 & 0.803 & 0.812 & 0.304 & 0.296 & 0.291 \\
\hline & \multirow{3}{*}{0.3} & 0.9 & 0.408 & 0.420 & 0.426 & 0.803 & 0.799 & 0.797 \\
\hline & & 0.5 & 0.627 & 0.644 & 0.654 & 0.536 & 0.527 & 0.521 \\
\hline & & 0.1 & 0.705 & 0.724 & 0.736 & 0.412 & 0.401 & 0.394 \\
\hline
\end{tabular}


Table A5: Sensitivity of $R I D E$ and $T E / O D E$ to $\boldsymbol{\varepsilon}$

$$
\delta=0.9, \quad \rho=0.1
$$

\begin{tabular}{|c|c|c|c|c|c|c|c|c|}
\hline \multirow{2}{*}{\multicolumn{3}{|c|}{$\varepsilon$}} & \multicolumn{3}{|c|}{$R I D E$} & \multicolumn{3}{|c|}{$T E / O D E$} \\
\hline & & & \multirow[t]{2}{*}{0.6} & \multirow[t]{2}{*}{0.8} & \multirow[t]{2}{*}{1.0} & \multirow[t]{2}{*}{0.6} & \multirow[t]{2}{*}{0.8} & \multirow[t]{2}{*}{1.0} \\
\hline$\gamma$ & $\beta$ & $\chi$ & & & & & & \\
\hline \multirow{9}{*}{1} & \multirow{3}{*}{0.1} & 0.9 & 1.680 & 1.639 & 1.615 & 8.448 & 8.359 & 8.306 \\
\hline & & 0.5 & 1.536 & 1.462 & 1.419 & 3.435 & 3.365 & 3.323 \\
\hline & & 0.1 & 1.648 & 1.540 & 1.475 & 2.259 & 2.193 & 2.154 \\
\hline & \multirow{3}{*}{0.2} & 0.9 & 2.322 & 2.246 & 2.201 & 7.857 & 7.729 & 7.654 \\
\hline & & 0.5 & 1.831 & 1.728 & 1.668 & 3.338 & 3.251 & 3.200 \\
\hline & & 0.1 & 1.876 & 1.738 & 1.657 & 2.238 & 2.159 & 2.113 \\
\hline & \multirow{3}{*}{0.3} & 0.9 & 3.023 & 2.898 & 2.824 & 7.589 & 7.416 & 7.316 \\
\hline & & 0.5 & 2.152 & 2.014 & 1.934 & 3.285 & 3.179 & 3.118 \\
\hline & & 0.1 & 2.124 & 1.951 & 1.851 & 2.231 & 2.139 & 2.085 \\
\hline \multirow{9}{*}{0.8} & \multirow{3}{*}{0.1} & 0.9 & 1.605 & 1.560 & 1.534 & 8.753 & 8.649 & 8.587 \\
\hline & & 0.5 & 1.570 & 1.484 & 1.432 & 3.560 & 3.475 & 3.424 \\
\hline & & 0.1 & 1.741 & 1.610 & 1.533 & 2.360 & 2.279 & 2.231 \\
\hline & \multirow{3}{*}{0.2} & 0.9 & 2.139 & 2.062 & 2.016 & 8.207 & 8.063 & 7.978 \\
\hline & & 0.5 & 1.831 & 1.715 & 1.647 & 3.490 & 3.386 & 3.326 \\
\hline & & 0.1 & 1.951 & 1.790 & 1.695 & 2.354 & 2.259 & 2.203 \\
\hline & \multirow{3}{*}{0.3} & 0.9 & 2.723 & 2.601 & 2.530 & 7.942 & 7.751 & 7.641 \\
\hline & & 0.5 & 2.114 & 1.963 & 1.876 & 3.455 & 3.331 & 3.259 \\
\hline & & 0.1 & 2.179 & 1.982 & 1.868 & 2.360 & 2.250 & 2.186 \\
\hline
\end{tabular}

It is clear from both these Tables that the ratio $T E / H^{0}$ is pretty insensitive to the value of the inverse elasticity, $\varepsilon$, which is why, in the text, we have reported values solely for $\varepsilon=0.8$.

We now explore the sensitivity of our measures of the total effectiveness of a CA's interventions to the model parameter $\delta$. To do this we set the inverse elasticity of demand to its central value $\varepsilon=0.8$ and let $\delta$ range over the 5 parameters $\delta=0.8,0.85,0.9,0.95,0.98$.

Table A4a (resp. A5a) reports results for the widest range of variation in $\delta$, namely, $\delta=0.8,0.9,0.98$. While we have also undertaken calculations for a narrower range of variation - namely $\delta=0.85,0.9,0.95$ - the results are much as to be expected from results reported, and are available from the authors on request. 
Table A4a: Sensitivity of $\bar{\Delta}$ and $T E / H^{0}$ to $\delta$

$$
\varepsilon=0.8, \quad \rho=0.1
$$

\begin{tabular}{|c|c|c|c|c|c|c|c|c|}
\hline & & \multirow[b]{2}{*}{$\delta$} & \multicolumn{3}{|c|}{$\bar{\Delta}$} & \multicolumn{3}{|c|}{$T E / H^{0}$} \\
\hline & & & \multirow[t]{2}{*}{0.8} & \multirow[t]{2}{*}{0.9} & \multirow[t]{2}{*}{0.98} & \multirow{2}{*}{0.8} & \multirow{2}{*}{0.9} & \multirow[t]{2}{*}{0.98} \\
\hline$\gamma$ & $\beta$ & $x$ & & & & & & \\
\hline \multirow{9}{*}{1} & \multirow{3}{*}{0.1} & 0.9 & 0.752 & 0.655 & 0.527 & 0.411 & 0.552 & 0.710 \\
\hline & & 0.5 & 0.852 & 0.829 & 0.810 & 0.242 & 0.281 & 0.315 \\
\hline & & 0.1 & 0.888 & 0.878 & 0.871 & 0.176 & 0.194 & 0.208 \\
\hline & \multirow{3}{*}{0.2} & 0.9 & 0.592 & 0.478 & 0.350 & 0.617 & 0.751 & 0.866 \\
\hline & & 0.5 & 0.735 & 0.701 & 0.672 & 0.411 & 0.463 & 0.507 \\
\hline & & 0.1 & 0.793 & 0.777 & 0.765 & 0.314 & 0.341 & 0.362 \\
\hline & \multirow{3}{*}{0.3} & 0.9 & 0.483 & 0.370 & 0.257 & 0.734 & 0.843 & 0.925 \\
\hline & & 0.5 & 0.640 & 0.602 & 0.569 & 0.532 & 0.587 & 0.631 \\
\hline & & 0.1 & 0.711 & 0.691 & 0.676 & 0.423 & 0.454 & 0.478 \\
\hline \multirow{9}{*}{0.8} & \multirow{3}{*}{0.1} & 0.9 & 0.786 & 0.700 & 0.580 & 0.355 & 0.488 & 0.649 \\
\hline & & 0.5 & 0.872 & 0.853 & 0.837 & 0.205 & 0.239 & 0.269 \\
\hline & & 0.1 & 0.902 & 0.895 & 0.888 & 0.149 & 0.164 & 0.176 \\
\hline & \multirow{3}{*}{0.2} & 0.9 & 0.639 & 0.530 & 0.400 & 0.555 & 0.694 & 0.826 \\
\hline & & 0.5 & 0.767 & 0.738 & 0.712 & 0.358 & 0.405 & 0.447 \\
\hline & & 0.1 & 0.817 & 0.803 & 0.793 & 0.271 & 0.296 & 0.314 \\
\hline & \multirow{3}{*}{0.3} & 0.9 & 0.532 & 0.420 & 0.299 & 0.677 & 0.799 & 0.898 \\
\hline & & 0.5 & 0.679 & 0.644 & 0.614 & 0.473 & 0.527 & 0.570 \\
\hline & & 0.1 & 0.742 & 0.724 & 0.711 & 0.372 & 0.401 & 0.423 \\
\hline
\end{tabular}


Table A5a: Sensitivity of $R I D E$ and $T E / O D E$ to $\boldsymbol{\delta}$

$$
\varepsilon=0.8, \quad \rho=0.1
$$

\begin{tabular}{|c|c|c|c|c|c|c|c|c|}
\hline \multirow{2}{*}{\multicolumn{3}{|c|}{$\delta$}} & \multicolumn{3}{|c|}{ RIDE } & \multicolumn{3}{|c|}{$T E / O D E$} \\
\hline & & & \multirow[t]{2}{*}{0.8} & \multirow[t]{2}{*}{0.9} & \multirow[t]{2}{*}{0.98} & \multirow[t]{2}{*}{0.8} & \multirow[t]{2}{*}{0.9} & \multirow[t]{2}{*}{0.98} \\
\hline$\gamma$ & $\beta$ & $\chi$ & & & & & & \\
\hline \multirow{9}{*}{1} & \multirow{3}{*}{0.1} & 0.9 & 1.495 & 1.639 & 1.976 & 5.535 & 8.359 & 13.349 \\
\hline & & 0.5 & 1.481 & 1.462 & 1.459 & 2.823 & 3.365 & 3.863 \\
\hline & & 0.1 & 1.577 & 1.540 & 1.517 & 1.970 & 2.193 & 2.373 \\
\hline & \multirow{3}{*}{0.2} & 0.9 & 1.894 & 2.246 & 2.979 & 5.127 & 7.729 & 12.191 \\
\hline & & 0.5 & 1.715 & 1.728 & 1.756 & 2.750 & 3.251 & 3.707 \\
\hline & & 0.1 & 1.764 & 1.738 & 1.726 & 1.948 & 2.159 & 2.349 \\
\hline & \multirow{3}{*}{0.3} & 0.9 & 2.32 & 2.898 & 4.057 & 4.950 & 7.416 & 11.726 \\
\hline & & 0.5 & 1.966 & 2.014 & 2.074 & 2.704 & 3.179 & 3.611 \\
\hline & & 0.1 & 1.965 & 1.951 & 1.949 & 1.936 & 2.139 & 2.302 \\
\hline \multirow{9}{*}{0.8} & \multirow{3}{*}{0.1} & 0.9 & 1.467 & 1.560 & 1.815 & 5.608 & 8.649 & 13.871 \\
\hline & & 0.5 & 1.521 & 1.484 & 1.466 & 2.921 & 3.475 & 3.986 \\
\hline & & 0.1 & 1.663 & 1.610 & 1.578 & 2.053 & 2.279 & 2.462 \\
\hline & \multirow{3}{*}{0.2} & 0.9 & 1.803 & 2.062 & 2.633 & 5.341 & 8.063 & 12.708 \\
\hline & & 0.5 & 1.728 & 1.715 & 1.722 & 2.868 & 3.386 & 3.861 \\
\hline & & 0.1 & 1.834 & 1.790 & 1.765 & 2.042 & 2.259 & 2.434 \\
\hline & \multirow{3}{*}{0.3} & 0.9 & 2.164 & 2.601 & 3.512 & 5.181 & 7.751 & 12.197 \\
\hline & & 0.5 & 1.949 & 1.963 & 1.996 & 2.836 & 3.331 & 3.782 \\
\hline & & 0.1 & 2.017 & 1.982 & 1.965 & 2.040 & 2.250 & 2.419 \\
\hline
\end{tabular}

We see that the conclusions - particularly those relating to the ratio of the Total Effect to the Observable Direct Effect, TE/ODE - are sensitive to the discount rate assumed.

\section{A3. Calculating the Marginal Effects of Competition Authority Interventions}

Using equations (41) - (44) and the calculations reported in Tables 1 and 3 we can calculate the marginal effects - in elasticity form - of an increase in each of the four enforcement parameters, $i=\beta, \gamma, \chi, \rho$. For each enforcement parameter we report the Total Effect $T E=\left(-\frac{\partial L}{\partial i} \cdot \frac{i}{L}\right)$, the Direct Effect $D E=\left(-\frac{\partial \sigma}{\partial i} \cdot \frac{i}{\sigma}\right)$ the Indirect Deterrence Effect $I D E=\left(-\frac{\partial \bar{\Delta}}{\partial i} \cdot \frac{i}{\bar{\Delta}}\right)$ and the Indirect Price Effect IPE $=\left(-\frac{\partial p^{C}}{\partial i} \cdot \frac{i}{p^{C}}\right)$, which are related by $T E=D E+I D E+\left(\eta\left(p^{C}\right) \cdot I P E\right)$. The factors that affect the magnitude of these effects differ across the enforcement parameters. Since $\beta$ operates through both its impact on $\sigma$ and its impact on $\tau$ the magnitudes of the effects depend on both $\sigma$ and $\varepsilon$. Since $\gamma$ operates solely 
through its effect on $\sigma$ the magnitudes of its effects depend solely on $\sigma$. While $\chi$ also operates only through its effect on $\sigma$, the magnitude of these effects depend on both $\sigma$ and $\chi$. Finally, since $\rho$ has no direct effect and operates solely through its impact on $\tau$ the magnitude of its impact depend on both $\sigma$ and $\varepsilon$.

As discussed in the text we undertake the calculations for three different values of $\sigma$ - namely $\sigma=0.413,0.753,0.927$ - and the uniquely associated values of $\beta, \gamma$ and $\chi$. We also use the central values for the remaining parameters - i.e. we have set $\delta=0.9, \rho=0.1, \varepsilon=0.8$.

Table A6b: Marginal Effects of Increases in $\beta$

\begin{tabular}{|c||c|c|c|}
\hline$\sigma$ & 0.927 & 0.753 & 0.413 \\
\hline$D E$ & 0.073 & 0.247 & 0.587 \\
\hline$I D E$ & 0.109 & 0.321 & 0.701 \\
\hline$I P E$ & -0.0036 & -0.0074 & -0.0113 \\
\hline$T E$ & 0.174 & 0.551 & 1.263 \\
\hline
\end{tabular}

Table A6b: Marginal Effects of Increases in $\gamma$

\begin{tabular}{|c||c|c|c|}
\hline$\sigma$ & 0.927 & 0.753 & 0.413 \\
\hline \hline$D E$ & 0.073 & 0.247 & 0.587 \\
\hline$I D E$ & 0.073 & 0.247 & 0.587 \\
\hline$I P E$ & 0 & 0 & 0 \\
\hline$T E$ & 0.146 & 0.494 & 1.174 \\
\hline
\end{tabular}

Table A6c: Marginal Effects of Increases in $\chi$

\begin{tabular}{|c||c|c|c|}
\hline$\sigma$ & 0.927 & 0.753 & 0.413 \\
\hline \hline$D E$ & 0.007 & 0.202 & 2.502 \\
\hline$I D E$ & 0.007 & 0.202 & 2.502 \\
\hline$I P E$ & 0 & 0 & 0 \\
\hline$T E$ & 0.014 & 0.404 & 5.005 \\
\hline
\end{tabular}

Table A6d: Marginal Effects of Increases in $\rho$

\begin{tabular}{|c||c|c|c|}
\hline$\sigma$ & 0.927 & 0.753 & 0.413 \\
\hline \hline$D E$ & 0 & 0 & 0 \\
\hline$I D E$ & 0.036 & 0.074 & 0.114 \\
\hline$I P E$ & -0.0036 & -0.0074 & -0.0113 \\
\hline$T E$ & 0.028 & 0.057 & 0.089 \\
\hline
\end{tabular}




\section{References}

Bageri, V., Y. Katsoulacos and G. Spagnolo (2013) "The Distortive Effects of Antitrust Fines Based on Revenue", The Economic Journal, 123 (572), 545-557.

Baker, J.B., (2003), “The case for antitrust enforcement”, Journal of Economic Perspectives 17 (4), 27.50 .

Bigoni, M., S.-O. Fridolfsson, C. Coq and G. Spagnolo, (2012), "Fines, leniency and rewards in antitrust", RAND Journal of Economics,43 (2), 368.390.

Bos, I., S. Davies and P.L. Ormosi, (2015), "The Deterrent Effect of Anti-Cartel Enforcement: A Tale of Two Tails" SSRN Electronic Journal, DOI:10.2139/ssrn.2471425.

Bryant, P.G., and E.W. Eckard, (1991), "Price Fixing: The Probability of Getting Caught," The Review of Economics and Statistics, 73, 531-536.

Buccirossi, P. and G. Spagnolo (2007) "Optimal Fines in the Era of Whistle blowers - Should Price Fixers Still Go to Prison?" in The Political Economy of Antitrust, by V. Goshal and J. Stennek (Eds.), Elsevier: Amsterdam.

Chang, M.H. and J.E. Harrington, (2010),"The Impact of a Corporate Leniency Program on Antitrust Enforcement and Cartelization", mimeo, available at: http://www.econ.jhu.edu/pdf/papers/WP548.pdf.

Connor, J.M. and R.H. Lande, (2012), 'Cartels as rational business strategy: new data demonstrates that crime pays', 34 Cardozo Law Review 427.

Connor, J.M. and R.H. Lande, (2013), "Cartel Fine Severity and the European Commission: 20072011, European Competition Law Review 34, 58-77.

Connor, J.M. (2015), “The Deterrent Power of Cartel Penalties", mimeo, presentation to Conference

"Looking Beyond the Direct Effects of the work of Competition Authorities: Deterrence and Macroeconomic Impact, Brussels 17-18 ${ }^{\text {th }}$ September 2015.

Available at: $\mathrm{http} / / / \mathrm{ec}$.europa.eu/competition/information/macroeconomy/index.html

Davies, S.W., and P.L. Ormosi,(2010) "Assessing Competition Policy: Methodologies, Gaps and Agenda for Future Research" CCP Working Paper, 10 - 19.

Davies, S.W. and P.L. Ormosi, (2012) "A comparative assessment of methodologies used to evaluate competition policy" Journal of Competition Law and Economics 8 (4),769.-803.

Davies, S.W. and P.L. Ormosi (2014) "The Economic Impact of Cartels and Anti-Cartel Enforcement"

Deloitte, (2007) The deterrent effect of competition enforcement by the OFT (Office of Fair Trading) 962.

Harrington, J. (2004) "Cartel Pricing Dynamics in the Presence of an Antitrust Authority," The Rand Journal of Economics 35, 651-673.

Harrington, J. (2005) "Optimal Cartel Pricing in the Presence of an Antitrust Authority," International Economic Review 46, 145-170. 
Harrington J. (2011) "When is an antitrust authority not aggressive enough in fighting cartels?," International Journal of Economic Theory 7, 39-50.

Harrington, J. (2014), "Penalties and the deterrence of unlawful collusion", Economics Letters, 124, 33-36.

Harrington J. and M. Chang (2009) "Modelling the Birth and Death of Cartels with an Application to Evaluating Antitrust Policy," Journal of the European Economic Association, 7(6), 1400-1435

Harrington J. and M. Chang (2015) "When Should We Expect a Corporate Leniency Program to Result in Fewer Cartels?," Journal of Law and Economics, forthcoming

Houba, H., E. Motchenkova, and Q. Wen (2010) "Antitrust enforcement with price-dependent fines and detection probabilities," Economics Bulletin, 30(3), 2017-2027.

Houba, H., E. Motchenkova, and Q. Wen (2012) "Competitive Prices as Optimal Cartel Prices", Economics Letters, 114(1), 39-42.

Katsoulacos, Y. and D. Ulph (2013) "Antitrust Penalties and the Implications of Empirical Evidence on Cartel Overcharges", The Economic Journal, 123 (572), 558-581.

Katsoulacos, Y., E. Motchenkova and D. Ulph, (2015). "Penalizing Cartels: The Case for Basing Penalties on Price Overcharge", International Journal of Industrial Organization, 42, pages 70-80.

Levenstein, M.C. and V.Y. Suslow (2011), "Breaking Up Is Hard to Do: Determinants of Cartel Duration", Journal of Law and Economics 54, 455- 92.

Levenstein, M.C. and V.Y. Suslow (2012), "Cartels and Collusion - Empirical Evidence". Ross School of Business Paper No. 1182. Available at SSRN: http://ssrn.com/abstract=2182565

Levenstein, M.C. and V.Y. Suslow (2014) "Price fixing hits home: an empirical study of price fixing conspiracies in the US", mimeo, University of Michigan, Jan. 2014.

London Economics, (2011), "The impact of competition interventions on compliance and deterrence." Office of Fair Trading, OFT1391.

Miller, N. H.,(2009). "Strategic Leniency and Cartel Enforcement." American Economic Review, 99, 750-768.

Ormosi, P. L., (2014), "A tip of the iceberg? the probability of catching cartels". Journal of Applied Econometrics 29 (4), 549.566.

Sorgard, L. (2015), "Merger Control (and more): Direct and Indirect Effect" mimeo, presentation to Conference "Looking Beyond the Direct Effects of the work of Competition Authorities: Deterrence and Macroeconomic Impact, Brussels 17-18 ${ }^{\text {th }}$ September 2015.

Available at: http://ec.europa.eu/competition/information/macroeconomy/index.html

Werden, G.J., (2008). "Assessing the effect of antitrust enforcement in the United States" De Economist 156 (4), 433.451. 